\title{
Dîme, production agricole et événements climatiques : le cas de Piura au nord du Pérou (17-19ème siècles)
}

Diezmo, producción agrícola y eventos climáticos: el caso de Piura en el norte del Perú (siglos XVII-XIX)

Tithes, agrarian production and climate events: the case of Piura in northern Peru (17th - 19th centuries)

Jakob Schlüpmann

\section{OpenEdition}

Journals

Édition électronique

URL : http://journals.openedition.org/bifea/6186

DOI : $10.4000 /$ bifea.6186

ISSN : 2076-5827

Éditeur

Institut Français d'Études Andines

Édition imprimée

Date de publication : 1 septembre 2003

Pagination : 263-292

ISSN : 0303-7495

\section{Référence électronique}

Jakob Schlüpmann, « Dîme, production agricole et événements climatiques : le cas de Piura au nord du Pérou (17-19ème siècles) », Bulletin de l'Institut français d'études andines [En ligne], 32 (2) | 2003, mis en ligne le 08 mai 2003, consulté le 02 décembre 2020. URL : http://journals.openedition.org/bifea/ 6186 ; DOI : https://doi.org/10.4000/bifea.6186

\section{cc)}

Les contenus du Bulletin de l'Institut français d'études andines sont mis à disposition selon les termes de la licence Creative Commons Attribution - Pas d'Utilisation Commerciale - Pas de Modification 4.0 International. 


\title{
DÎME, PRODUCTION AGRICOLE ET ÉVÉNEMENTS CLIMATIQUES : LE CAS DE PIURA AU NORD DU PÉROU (17-19 ${ }^{\text {ÈME }}$ SIÈCLES)
}

Jakob SCHLÜPMANN*

\begin{abstract}
Résumé
L'utilité de la dîme comme mesure de production agraire et par extension comme révélateur d'événements et de changements climatiques en Amérique latine reste débattue. Pour apporter des éléments à ce débat, cet article analyse les pratiques d'affermage de la dîme et l'évolution des montants collectés pour la région de Piura au nord du Pérou à l'époque coloniale. Il détaille les procédés qui mènent à la constitution des séries décimales, montre la longue croissance de la production agraire entre le $17^{\text {ème }}$ et le $18^{\text {ème }}$ siècle, l'apogée des revenus de la dîme dans la seconde moitié du $18^{\text {ème }}$ siècle, puis le retournement dès les premières années du $19^{\text {ème }}$ siècle. Il souligne que ces séries décimales décèlent les principales sécheresses qui affectèrent la zone à l'époque coloniale mais relativise la portée de ces chiffres pour une histoire climatique en l'absence de sources pour le $17^{\text {ème }}$ siècle et de données complémentaires, en particulier d'un indice de prix régional.
\end{abstract}

Mots clés : Histoire agraire, histoire climatique, dîme, conjoncture économique, Piura, Pérou, époque coloniale, $17^{\text {ème }}$ et $18^{\text {ème }}$ siècles.

\section{DIEZMO, PRODUCCIÓN AGRÍCOLA Y EVENTOS CLIMÁTICOS: EL CASO DE PIURA EN EL NORTE DEL PERÚ (SIGLOS XVII-XIX)}

\section{Resumen}

La utilidad del diezmo como medida de producción agraria y por extensión como indicador de eventos y cambios climáticos en América latina sigue en debate. Este artículo se propone analizar las prácticas de arrendamiento del diezmo y su evolución para la región de Piura en el norte del Perú en la época colonial. Detalla los pasos que llevan a la constitución de series decimales, muestra el sostenido crecimiento de la producción agraria de la región entre el siglo XVII y XVIII, el apogeo de los diezmos en la segunda mitad del siglo XVIII, y el inicio del decaimiento ya en los primeros años del siglo XIX. Subraya que las series de diezmos descubren las principales sequías que afectaron la zona en la época colonial pero cuestiona el alcance de estas cifras para una historia climática general en ausencia de fuentes para el siglo XVII y datos complementarios como un índice de precios regional.

Palabras claves: Historia agraria, historia climática, diezmo, coyuntura económica, Piura, Perú, época colonial, siglo XVII y XVIII.

\footnotetext{
*4, rue de Palestine 75019 Paris. E-mail : js@aleph99.org
} 


\title{
TITHES, AGRARIAN PRODUCTION AND CLIMATE EVENTS: THE CASE OF PIURA IN NORTHERN PERU (17TH - 19TH CENTURIES)
}

\begin{abstract}
The usefulness of tithes as a measure of agrarian production and also as a way to reveal climate events and changes in Latin America is still debated. This article analyzes the practice of farming out tithes and the evolution of their revenue over two and half centuries in Piura, northern Peru. It details the steps that allow the establishment of a tithes series and shows the steady growth of agrarian production in the Piura region between the 17th and 18th centuries, the tithe receipts peak during the second half of the 18th century, and a downturn occurs in the first years of the 19th century. The tithe patterns reveal a series of the major droughts, which affected Piura in colonial times, but the article questions the value of such figures for climate history in general, given the absence of sources for the 17th century as well as complementary data such as a regional price index .
\end{abstract}

Keywords: Agrarian history, climate history, tithes, economic trends, Piura, Peru, colonial times, 17th-18th centuries.

La pertinence de la dîme comme indicateur de l'évolution du niveau de production agricole est un sujet qui a déjà été amplement débattu dans l'historiographie de l'Amérique latine. Si les " tares" de la dîme monétarisée utilisée littéralement et sans discernement sont bien reconnues (1), son usage sur un espace délimité dont les principales étapes historiques ont préalablement été déterminées semble concevable (2). Notre objectif dans ce travail est de reprendre l'analyse du fonctionnement de la dîme dans une région particulière, de constituer une série des plus complètes possibles et de la comparer avec un ensemble de données qualitatives afin de voir si les fluctuations de cette série sont effectivement révélatrices de problèmes agraires, de ruptures de production.

La région de Piura que nous nous proposons d'examiner présente un intérêt particulier par l'alternance marquée de longues périodes sèches et d'années très humides liées aux oscillations climatiques du Pacifique sud. L'utilisation de la dîme, tant comme indicateur des variations de production agraire à court terme que comme mesure de l'évolution sur la longue durée de l'économie régionale, y présente les mêmes importants problèmes d'ordre méthodologique qu'ailleurs. Mais ces alternances climatiques marquées devraient permettre de mieux comprendre l'effet des accidents de production sur l'évolution de la dîme et inversement, de montrer si des ruptures dans sa courbe sont probantes de sécheresses ou de pluies prolongées, en somme si une série décimale peut sérieusement servir d'indicateur climatique sur le temps court.

Les variables qui interviennent sur la dîme monétarisée sont multiples : une analyse rigoureuse de ce droit est ainsi nécessaire pour comprendre son évolution, départager une conjoncture économique (prix, marchés) des facteurs qui affectèrent

(1) Pour l'Amérique latine, voir en particulier le débat autour de l'article de Ouweneel \& Bijleveld, 1989. Voir aussi Tandeter, 1995.

(2) Comme le fait remarquer Guerrero Soriano, 1994. Voir aussi Cervantes Bello, 1999. 
directement la productivité agraire. Pour ce faire, nous décortiquerons d'abord les différentes phases qui mènent à la constitution des séries décimales et déterminerons les périodes pour lesquelles les sources sont disponibles. Puis nous examinerons l'évolution générale de la dîme à Piura. Enfin, nous jugerons si les "accidents" climatiques reconnus qui affectèrent la production se reflètent dans la série obtenue et dans quelle mesure l'évolution de cette série est corroborée par des donnés qualitatives et évènementielles — en particulier climatiques — acquises par ailleurs.

\section{ASSIETTE ET COLLECTE DE LA DÎME}

Dîme et prémices constituent les seules sources nous permettant d'approcher la production agricole à Piura dans la durée. La taxe de l'alcabala, un droit à priori sur le commerce et les échanges, sous sa forme de capitation (cabezón) frappait bien les exploitations agricoles, mais proportionnellement à leur taille plutôt qu'en fonction de leur production réelle. Pas de série sur des moulins, aucune comptabilité d'hacienda suffisamment durable, aucun affermage assez détaillé sur un temps long (3). Rien ne nous permet d'accompagner, de mettre en perspective le prélèvement décimal sur deux siècles. Seule information isolée sur l'évolution du niveau des revenus de la terre, il importe d'autant plus de comprendre sa portée et tout simplement à quel point la dîme est réellement le prélèvement d'un dixième de la production régionale.

Il est donc d'abord nécessaire de s'interroger sur les particularités qui s'appliquaient à un espace où la propriété de la terre s'exprimait dans les formes les plus diverses allant du grand domaine à la propriété communautaire des réductions. Quel rapport en effet entre les grands propriétaires des quelques 60 haciendas constituées au cours du $17^{\text {ème }}$ siècle, les Indiens des terres rognées des réductions de Catacaos, Ayabaca, Frías, Huancabamba, Huarmaca ou encore les “ petits" blancs et métis qui créèrent la petite propriété autour de Chalaco vers la fin du $17^{\text {ème }}$ siècle ? Qui payait la dîme? Et sur quelles productions ?

Dans le cas des haciendas l'assiette du prélèvement décimal était simple : les comptes des grandes propriétés montrent que les hacendados, de la sierra comme de la côte, avaient à céder précisément la dixième partie de leurs récoltes et le dixième de la reproduction du bétail (sans escompter les frais de production, les semences).

Mais d'après un rapport présenté par le curé de Piura aux autorités ecclésiastiques, tous les “ producteurs " de Piura, n'étaient pas à la même enseigne. Ainsi, même si les Indiens payaient effectivement la dîme, ils contribuaient sur la base de taux divers et surtout, étaient exemptés dans le cas de certaines cultures (4):

(3) Hormis quelques chiffres sur l'affermage du troupeau de petit bétail du couvent de la Merced, qui reflète la longue et constante baisse de la rentabilité des ovins et caprins pour l'industrie du savon sur la côte. Affermé pour 240 pesos entre 1635-1652, le troupeau de quelques 1500 têtes ne rapporte plus que 150 pesos entre 1660 et 1716, tombe à 140 pesos en 1719, puis à 100 pesos entre 1738 et 1774 . À partir de 1786 jusqu'au début du $19^{\text {ème }}$ siècle, il ne rapporta qu'entre 50 et 100 pesos annuellement au couvent (voir Schlüpmann, 1993-1994 : 180).

(4) Pour le Pérou, les historiens en sont encore à se demander si les Indiens étaient exemptés du payement de la dîme. $C f$. Haitin, 1985 : 170-171; Carmagnani, 1973 : 195. 
"en cumplimiento de la superior orden de su excelencia y de lo pedido por el señor fiscal en su ultima visita de lo que debo informar a su excelencia serca de los usos y costumbres que tienen los yndios de los pueblos de esta provincia de Piura de pagar los diezmos a Nuestra Santa Madre Iglesia es que de los ganados bacunos y caballeros pagan de dies uno y del trigo lo mismo, pero de las papas, ajos, alberjas, quinina y legumbre no pagan cosa alguna, siendo assi que de estos frutos sembran y cosechan mas que del trigo, esto es Excelentissimo Señor en los pueblos de la sierra, pero en los de los balles y haziendas pagan de dies uno assi de los ganados como de los demas frutos por que esta es la costumbre que de immemorial tiempo desta parte han observado los yndios para pagar su diezmos y los diezmeros para cobrar los, a excepcion de los indios del pueblo de Colan, que de sus semillas de la tierra, pagan uno de veinte, y no de dies, arreglando se dicho pueblo, que es cuanto en particular puede y debo informar a su Excelencia con verdad y asi lo juro por Dios Nuestro Señor y una señal de cruz, segun dicho. Piura, Agosto nueve de mill setecientos sesenta y cuatro año. Manuel Seminario y Saldivaz " (Archivo General de la Nación (AGNP), Derecho Indígena, leg. 18, cuad. 313, 1764)...

Ce rapport se fondait sur le témoignage d'anciens fermiers de la dîme. Mais, s'il se conformait en tout point à la déposition de don Antonio de Salcedo qui avait été fermier de la dîme pour Ayabaca en 1719 et 1720 ou encore à celle de don Francisco de Irarrazabal y Andia, fermier de la dîme pour Huancabamba en 1749 et 1750, en revanche, il omettait les avis d'autres fermiers selon lesquels les Indiens ne payaient que le vingtième des cassonades, ou le dixième des fromages produits par le lait d'une vache sur trois (Archivo General de la Nación (AGNP), Derecho Indígena, leg. 18, cuad. 313,1764 ) Sur la côte, théoriquement donc, un indice de la dîme prélevé en nature aurait été un indice relativement fidèle de la production agraire en général. Pour la "sierra", ce lien est moins évident, particulièrement là où la population indigène était importante : l'absence d'une bonne part des cultures dans " l'assiette " de la dîme y fausse la serie décimale comme indice général de production.

Quelle était la circonscription territoriale de la dîme de Piura ? Les divisions administratives ecclésiastiques se superposaient-elles au découpage administratif laïc ? Au $17^{\text {ème }}$ siècle ce n'était pas le cas, puisque selon les livres de comptabilité, deux circonscriptions de la dîme contribuaient au titre du noveno aux caisses royales de Piura. D'une part, la circonscription de la " dicha ciudad de Piura" ou "vicaria de Piura" et de l'autre celle de "Olmos, Motupe y los demas pueblos de su vicaria". Selon l'intitulé de la rubrique correspondante dans les livres des caisses royales, le noveno de Motupe et Jayanca continua d'être versé dans les caisses de Piura jusqu'en 1727, ultime date à laquelle ces caisses recensent encore un versement de 219 pesos 4 réaux qui correspondait à la rubrique noveno (AGNP. C17 Cajas Reales Piura, leg. 1207, cuad. 51). De toute évidence, la dîme de Motupe qui était de 3 à 4 fois inférieure à celle du vicariat de Piura au début du $18^{\text {ème }}$ siècle, appartenait depuis longtemps à la sphère d'influence de Lambayeque comme le souligne la provenance de ses fermiers. Son rattachement à Piura paraissait un anachronisme qui prit fin en 1728, même si les vallées de Olmos et Motupe continuèrent de faire partie du corregimiento de Piura. À partir de cette année, seul le noveno du vicariat contribua aux caisses royales. Un espace qui comprenait Tumbez à l'extrême nord, les vallée du Chira et du Piura sur la côte, 
la sierra de Ayabaca à Huarmaca à l'est : en somme, le corregimiento de Piura amputé des vallées d'Olmos et Motupe. La dîme du vicariat de Piura était subdivisée en cinq perceptions - Huancabamba, Ayabaca, Santa Ana, La Chira-Tumbez, Catacaos. Elle était administrée par le Chapitre, la "mesa capitular", de l'évêché de Trujillo dont dépendait le vicariat.

Toutes les sources montrent que la dîme de Piura fut toujours affermée et jamais administrée directement par l'Église. Le droit de percevoir la dîme était adjugé au dernier enchérisseur lors de mises aux enchères qui se tenaient au début de la période à concéder. En 1645, le procès-verbal des enchères de la dîme nous détaille la procédure : dès fin janvier fut proclamée la mise aux enchères de la dîme. Le 9 mars se réunirent devant l'hôpital de Santa Ana de la ville de Piura, le curé Juan de Mori Alvarado, commissaire chargé du recouvrement de la dîme, les deux officiers royaux de la circoncription et le crieur public pour procéder aux enchères. Juan Prieto Dávila, vecino de Piura, fut le premier à offrir 4000 pesos pour l'ensemble de la dîme du corregimiento. Après une courte lutte avec Antonio Velasquez qui améliora sa mise de 100 pesos puis encore de

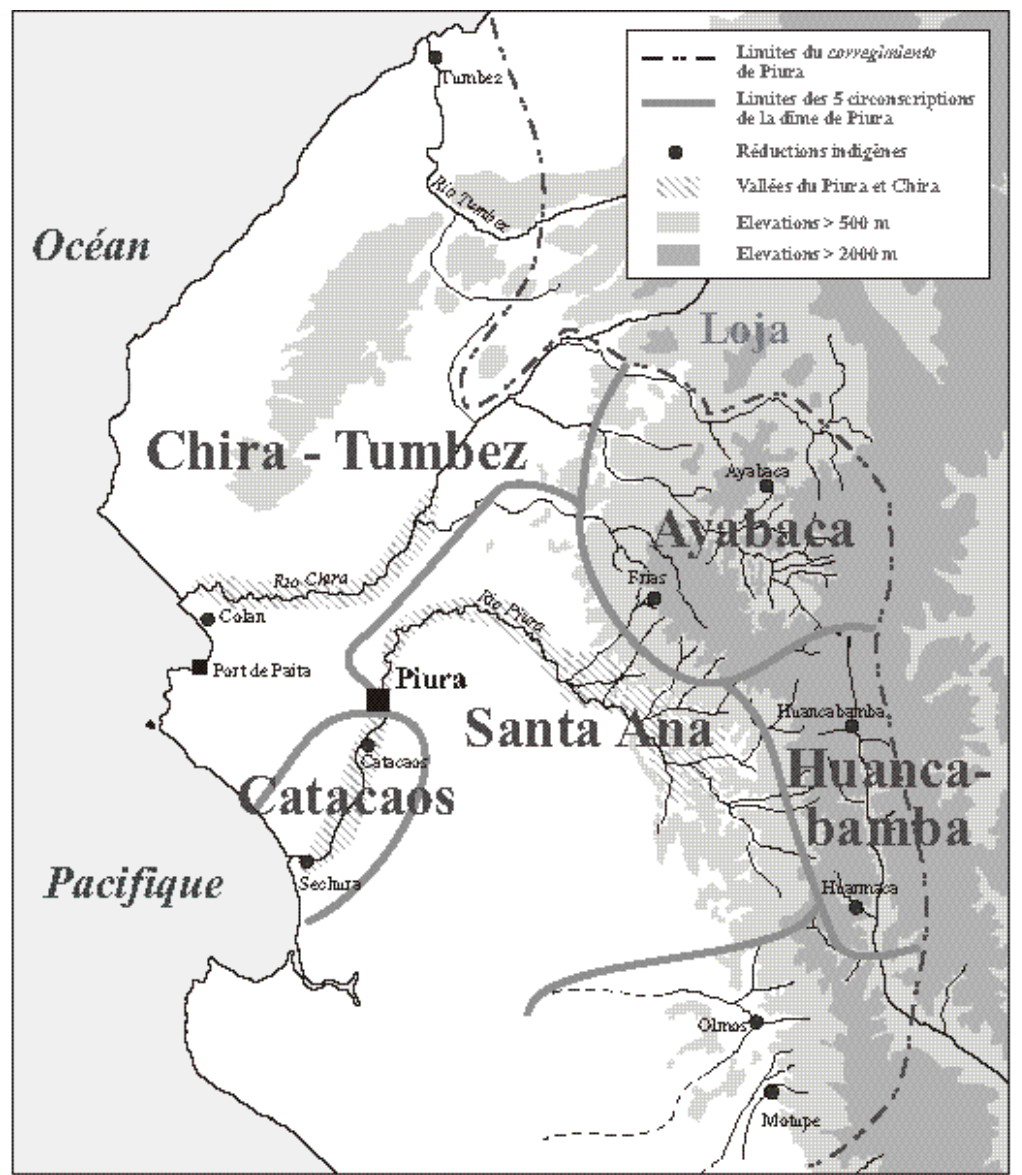

Fig. 1 - Les circonscriptions de la dîme à Piura. 
10 pesos, Dávila emporta les enchères pour 4220 pesos de 9 réaux (5). Le 16 mars était établi l'acte de l'affermage qui, par ailleurs, instituait Diego de Saavedra, autre citoyen éminent de Piura et futur grand propriétiare foncier, garant du fermier. Dès le 31 mars, l'information avait été transmise à Trujillo, où la " Mesa Capitular " établissait le montant de la part à verser aux caisses royales.

D'autres exemples le disent encore, le début du mois de mars resta tout au long de l'époque coloniale, l'époque des enchères de la dîme : les fermiers estimaient donc les récoltes sur la base de l'état des cultures et troupeaux de bétail observé en janvier et février.

$\mathrm{Au} 17^{\text {ème }}$ siècle, la perception de la dîme était adjugée pour une année. À partir de 1697 au moins, l'affermage se concédait systématiquement par biennales.

Selon le cas, la dîme pour l'ensemble de la vicaria de Piura était prise à ferme par un seul fermier "général " ou chacune des perceptions adjugées à des fermiers différents. Entre 1725 et 1800 , sur une trentaine d'affermages dont nous avons les détails, un tiers environ fut adjugé par le Chapitre à un seul fermier principal. Rien n'interdisait cependant à ce fermier principal de sous-affermer les circonscriptions à d'autres fermiers : ce fut par exemple le cas du capitaine Sebastian Fernandes Morante, plusieurs années de suite le fermier de l'ensemble de la dîme au 17ème siècle, qui " sous afferma " en 1658 le partido de la Chira à Juan Corco pour 850 pesos.

Lorsque l'affermage de la dîme était distribué sur plusieurs fermiers, il n'était pas rare que l'un ou l'autre de ces fermiers s'adjugeât deux circonscriptions. Pour la biennale 1777-1778, par exemple, la dîme fut répartie entre quatre fermiers : le capitaine don Manuel de León affermant à la fois le partido de Santa Ana et celui de Catacaos.

En 1785, un seul fermier - don Manuel Besada — s'octroya même les 4 principaux partidos pour 22220 pesos et ne laissa que la maigre dîme de Catacaos à un deuxième fermier - don Juan Ignacio de Leon y Gastelú — pour 850 pesos. D'une manière générale cependant, aucune différence notoire du montant global de l'affermage n'est à noter entre les affermages fractionnés et la concession en bloc de la dîme de Piura.

Qui étaient les fermiers de la dîme? Généralement les grands propriétaires fonciers de Piura. Le capitaine don Sebastian Fernandez Morante par exemple, déjà mentionné, fermier au $17^{\text {ème }}$ siècle, fut le propriétaire de Yapatera et de Malingas, deux grands domaines du Haut-Piura. L'alferez real don Juan Gervacio de Taboada, plusieurs

(5) " en la ciudad de San Miguel de Piura en nueve dias del mes de marzo de mill y seiscientos y quarenta y cinco años = A las puertas del hospital de Señora Santa Ana desta ciudad presentes el Bachiller Juan de Mori Alvarado, cura y vicario del pueblo de Catacaos comissario del Santo Oficio y Santa Cruzada en ella y su partido juez para el hacimiento de las rentas decimales de la vicaria della este dho año Tesorero Miguel de Axpurua Contador capitan Isidro de Céspedes jueces oficiales reales por lo que toca al interes de Su Magestad por voz de Juan de Villegas negro pregonero se dio el ultimo pregon a las dhas rentas y estandose pregonando algunos partidos de la jurisdicción diciendo el dho pregornero la cantidad que se dara por cada partido parecio Juan Prieto Dávila vecino de esta ciudad [...] dixo que hacia postura en la dha gruesa de diesmos de la vicaria de esta dha ciudad... ". Archivo de Límites del Ministerio de Relaciones Exteriores de Perú (ALMRE), LEB-4-32, 1645. 
Tableau 1 - Fermiers de la gruesa de la dîme de Piura.

\begin{tabular}{|l|l|c|c|}
\hline Biennale & Fermier & $\begin{array}{c}\text { Montant en pesos } \\
\text { de la Gruesa }\end{array}$ & $\begin{array}{c}\text { Noveno en pesos,, } \\
\text { réaux }\end{array}$ \\
\hline $1729-1730$ & Don Antonio de Talledo & 18600 & $1881,, 6$ \\
$1731-1732$ & Don Diego de Mesones & 21000 & $2195,, 3$ \\
$1735-1736$ & Don Antonio Rodriguez de Taboada & 20000 & $2090,, 3$ \\
$1737-1738$ & Don Diego de Saavedra & 17600 & 1840,0 \\
$1741-1742$ & Don Manuel de la Cruz y Castilla & 16400 & $1713,, 0$ \\
$1745-1746$ & Don Diego de Saavedra & 21500 & 2247,4 \\
$1751-1752$ & Don Manuel Gonzales Carrasco & 24760 & $2587,, 6$ \\
$1761-1762$ & Don Juan Gervacio de Taboada & 20500 & $2121,, 4$ \\
$1773-1774$ & Don Pedro Martin Ramos & 19000 & $?$ \\
$1775-1776$ & Don Luis de Mesones y la Portilla & 18500 & $2055,, 0$ \\
$1791-1792$ & Don Juan Christobal de la Cruz & 26160 & $?$ \\
\hline
\end{tabular}

Les montants de la gruesa en italique sont des montants calculés à partir du noveno.

Source : AGNP. C17 Cajas Reales Piura, leg. 1207-1222.

fois de suite fermier de la dîme dans la seconde moitié du $18^{\text {ème }}$ siècle et successeur de son père don Antonio Rodriguez de Taboada, fut le propriétaire de La Matanza, Pabur et Chapica, l'un des plus grands ensembles d'haciendas du corregimiento de Piura; C'était encore le cas de Diego de Saavedra, Manuel Gonzales Carrasco, le regidor Luis de Mesones y la Portilla, tous hacendados de l'un ou l'autre des grands domaines de Piura. D'une manière générale, et à l'épreuve d'une étude plus détaillée, la composition sociale des fermiers, à l'image de la société piurana de l'époque, ne subit aucune transformation radicale qui eut pu perturber ou avoir un impact marqué sur la courbe décimale. Voyons alors de quelle manière le paiement des affermages pouvait influer sur cette courbe.

Une fois la dîme adjugée, les fermiers étaient tenus de verser le montant des affermages selon un échéancier déterminé : au $17^{\text {ème }}$ siècle lorsqu'elle s'affermait annuellement, une première moitié était versée en milieu d'année pour la "San Juan ", une deuxième en fin d'année pour Noël. Lorsqu'à partir de la fin du $17^{\text {mème }}$ siècle, la dîme était adjugée pour deux ans, les versements étaient supposés s'effectuer en quatre fois au mois d'août de la première année de l'affermage, aux mois de février et août de la seconde année et l'ultime échéance au mois de février de l'année qui suivait la fin la période affermée. Mais dans les faits, les règlements de ces montants au Chapitre étaient irréguliers et s'échelonnaient sur de nombreuses années : lorsqu'en 1770, le docteur don Juan Manuel de León y Encalada, curé et vicaire, commissaire chargé du recouvrement des affermages, dû rendre compte de son administration de la dîme pour la décennie de 1760, il s'avéra que non moins de 18 fermiers avaient réglé des soldes de leur affermage encore antérieurs à cette décennie. Le fermier de la dîme de 
Catacaos pour la biennale de 1743-1744 paya ainsi en 1764, plus de vingt ans après la mise aux enchères, un reliquat de 186 pesos 6 réaux. Pablo Jaime, fermier de la dîme de Huancabamba pour 1747-1748, don Joseph Tineo fermier de Ayabaca pour 17471748, Tiburcio de Biera, fermier de Catacaos pour 1751-1752 ou encore don Phelipe Carrasco, fermier de Huancabamba en 1751-1752..., tous payèrent encore des reliquats de leur bail, dix à quinze années après la fin de leur fermage (Archivo Episcopal de Piura [AEP]. Causas civiles, leg. 5, exp. 63. Autos sobre la cuenta de cargo y data que don Miguel Guillermo Bobadilla le formó al doctor don Juan Manuel de León y Encalada. 17-02-1770).

Autre exemple, celui-ci pour la biennale de 1799-1800, don Fernando Seminario avait affermé le partido de Ayabaca pour 7095 pesos 2 réaux. Le 17 janvier 1800, il versait un premier montant de 1000 pesos au commissaire chargé du recouvrement. Trois autres versements suivirent au cours de cette même année, de sorte que le 20 juillet 1800, il ne manquait qu'un peu plus de 500 pesos pour solder les comptes. Cette ultime part ne fut versée aux recettes de l'Église que le 13 mars 1802, plus d'un an après la fin de l'affermage (AEP. Causas civiles, leg. 10, exp. 142).

Un travail sur les montants effectivement payés par les fermiers pourraient être un indice des moments difficiles que traversait tel ou tel partido et donc un meilleur indicateur des problèmes de production, mais cette approche s'avère impossible dans la pratique : des sources continues de toute la comptabilité de la dîme serait nécessaire pour obtenir l'ensemble des versements étalés effectués par les fermiers. Elles ne sont pas disponibles.

De même, le cas du noveno des caisses royales souligne le décalage entre l'adjudication de la dîme et l'arrivée dans les caisses des premiers ou derniers versements. Les " juezes de diezmo" du Chapitre de Trujillo qui supervisaient l'adjudication de la dîme de Piura, étaient chargés d'établir la " nema", billet qui calculait le montant du noveno en fonction du montant de l'affermage. Il faisaient parvenir ce billet aux officiers royaux des caisses de Piura et émettaient une lettre de créance pour le montant du noveno à tirer sur l'un ou l'autre des fermiers de la dîme. Normalement, le noveno devait être versé en quatre tranches, sur le modèle des versements du montant d'affermage de la dîme au Chapitre. Mais encore une fois, les échéances étaient rarement respectées. En 1732 par exemple, la dîme de Piura pour 1733-1734 fut adjugée à plusieurs fermiers. Les juges de la mesa capitular émirent de ce fait plusieurs lettres de créances qui engageaient entre autres don Bernardino Gonzales Carrasco, fermier du partido de Huancabamba, à payer une partie du noveno aux caisses royales : le dernier paiement effectué au titre de ce noveno par Don Bernardino le fut seulement en novembre 1736, soit près de deux années après la fin de l'affermage (AGNP. C17 Cajas Reales Piura, leg. 210, cuad. 99).

Autre exemple : fin 1754, la dîme de Santa Ana des années 1755-1756 fut adjugée à don Manuel de la Cruz y Castilla. Au cours de l'affermage, l'évêché de Trujillo émis sur son nom un billet de 2691 pesos 2 réaux au titre du noveno à payer aux caisses royales. Mais Manuel de la Cruz y Castilla n'effectua un premier versement de 1425 pesos qu'en septembre 1758 et ne régla le solde - 1266 pesos 2 réaux - qu'en février 1760, soit plus de 3 ans après la fin de son affermage (AGNP. C17 Cajas Reales Piura, 
leg. 215, cuad. 235). Les atermoiements dans les versements du noveno étaient donc plutôt la règle que l'exception.

Parfois, les propres juges de la dîme de Trujillo ne remettaient pas dans les délais la " nema", de sorte que les officiers royaux n'étaient pas en mesure de collecter la fraction exacte de la dîme qui correspondait aux caisses royales et prélevaient une somme forfaitaire qui était régularisée ultérieurement (6). Dans d'autres circonstances, des événements sans rapport avec la production agricole affectèrent fortement les versements du noveno dans les caisses : ce fut par exemple le cas en 1741, lorsque les 1600 pesos que remis la fille de don Pedro de Soto, fermier de la dîme, à don Nicolas Gonzales de Zalasar, contador en poste à Paita, furent saisis dans l'attaque du port par le corsaire anglais Anson. Des 1808 pesos de noveno qui revenaient théoriquement à la couronne, seuls 208 pesos furent en fin de compte effectivement versés et enregistrés dans les livres de compte.

Ces exemples montrent le danger d'utiliser sans discernement le " cargo" du noveno enregistré dans les livres de la comptabilité vice-royale, qui n'est finalement que le solde annuel des versements, à un rythme qui lui est propre, finalement très éloigné d'une conjoncture agraire. Ils soulignent que dans la pratique seuls les montants même de l'affermage de la dîme qui collent au plus près des estimations de récoltes et possibilité de ventes, sont en mesure de donner une information sérielle exploitable sur l'évolution de la production agraire.

Cependant, dans la mesure où ces indications sur la dîme ne sont pas les volumes de la production, mais uniquement les montants en pesos de son affermage, la compréhension des mécanismes de recouvrement et de transformation des produits agricoles en revenu monétaire serait essentiel à un usage précis de la dîme comme baromètre de production. Comment en effet étaient vendus les produits de la dîme ? Quelle était la marge de profit du fermier général, des sous-fermiers lorsqu'il y en avait ? Quel fut le rôle des marchés, des prix sur les accidents de conjoncture, sur l'évolution du montant de la dîme? Autant d'éléments qui nous font malheureusement défaut dans le cas de Piura, puisque nous n'avons pas pu trouver d'affaires traitant de cette collecte de la dîme auprès des producteurs que ce soit dans les haciendas, les réductions indigènes ou les petits propriétaires de la sierra. Certes, les comptes d'haciendas nous détaillent souvent la part dévolue à la dîme, mais aucune comptabilité de fermier, aucun litige sur

(6) “ debidos cobrar a don Nicolas de Cordoba arrendatario de los diezmos del partido del pueblo de Ayabaca en el presente viennio de 769 y 770 cuia gruesa se remato en la cantidad de dies $y$ ocho mil docientos quarenta y dos pesos de a 8 y tocandole a Su Magestad por sus dos reales novenos un mill ochocientos ochenta y ocho pesos en los quatro tercios como consta de la nema y distribucion echa por los juezes de diezmos de la ciudad de Trujillo que es documento $n^{\circ} 7$ se ha elegido al espresado deudor por ser lo de mas brebe y facil paga, como tambien sus fiadores y haviendose cumplido el primer tercio ... en el mes de agosto de este presente año no se han podito recaudar dichos pesos por haverse remitido de la ciudad de Trujillo dicha nema y su respectiba libransa en el inmediato corr $^{\circ}$ de 26 del presente mes como se haze constar por la fecha de la sitada nema a $1^{\circ}$ del presente mes de diziembre sin embargo de haverse pedido con la debida anticipacion y por hallarse tambien el dicho deudor en el pueblo de Ayabaca a distancia de cuarenta leguas de esta ciudad adonde se le a dirigido carta por que en el termino que se le a señalado comparesca ...". AGNP. C17 Cajas Reales Piura, leg. 1220, cuad. 323. 
le " quotidien " de la perception, aucun dossier sur la commercialisation de ce dixième de la production agricole de Piura n'ont pu être repérés jusqu'à présent.

Nous ne savons d'ailleurs même pas quels furent les produits qui influaient le plus fortement sur le montant de l'affermage de la dîme. Si, selon le fermier de l'alcabala, encore au début du $18^{\text {ème }}$ siècle, le commerce des produits de l'élevage représentait la plus grande partie des activités marchandes, dans les premières décennies du $18^{\text {ème }}$ siècle, le développement de la frontière agricole diversifia la production régionale. Ainsi d'après les registres de Paita, (si l'on excepte la cascarilla de Loja), à côté du savon et des cuirs, les principaux produits en valeur exportés par le port de Piura était le blé sous forme de farine, le sucre et le coton. Impossible cependant d'affirmer lesquels de ces produits jouaient un rôle majeur dans la définition du montant de la dîme.

L'approche de la dîme par les montants de son affermage restera donc nécessairement sommaire, mais la seule possible dans le cadre des sources rencontrées. Voyons donc quels fonds d'archives nous permettent de retrouver les montants d'affermages et s'ils permettent la constitution d'une véritable série homogène.

\section{DESTINATAIRES ET SOURCES}

Pour comprendre quelles institutions ont pu laisser des traces quant au montant de la dîme collectée au travers du système de l'affermage, il est nécessaire de faire l'inventaire de l'ensemble des destinataires de cette manne.

La règle générale, largement documentée pour l'Amérique espagnole, précise que la dîme se divisait en 4 parts égales, dont un quart pour le prélat, un deuxième quart pour le dean et le cabildo. Les deux autres quarts étaient divisés en 9 parts (novenos), dont deux étaient destinés à la couronne, une part et demi à l'hôpital, une autre part et demi à la fabrication d'églises, et les quatre neuvièmes restants aux curés et autres "salariés" de l'église.

De ce fait, les données sur la dîme à Piura se trouvent aussi bien dans le fonds des caisses royales que dans les archives des institutions ecclésiastiques. Une bonne partie des sources pour reconstituer les séries de la dîme se retrouve aussi dans les protocoles de notaires, où furent enregistrées les ventes aux enchères et les écritures de cautions qui garantissaient la solvabilité des fermiers.

Les premières données sérielles existantes pour Piura, se rencontrent dans la comptabilité des caisses royales du début du $17^{\text {ème }}$ siècle dont une copie existe à Séville dans l'Archivo General de Indias (AGI) pour les années 1600 à 1606. Les officiers royaux enregistrèrent non seulement la somme du noveno, mais annotèrent aussi le montant des affermages même de la dîme. Malheureusement, pour la majeure partie du $17^{\text {ème }}$ siècle restant, les sources sérielles font défaut, tant pour le noveno des caisses royales que pour les enchères en général. En l'absence des cahiers même de la mesa capitular de Trujillo, seuls quelques enchères décimales isolées, découvertes au détour d'une affaire, d'un protocole de notaire, ont pu donner une information fragmentée.

Ce n'est qu'à partir de 1690 que l'existence de livres de comptes des caisses royales de Piura nous permet de reconstituer une véritable série (Tepaske \& Klein, 1982 et AGN, C17 Cajas Reales, Piura, leg. 1 -20). Souvent, cependant, le montant 
de l'affermage même n'est pas disponible, mais uniquement le noveno que le fermier se devait de régler aux officiers royaux : la méthode de calcul du noveno n'étant pas toujours la même, il est alors parfois nécessaire de " deviner " à quelques pesos près le montant précis de l'affermage. Entre 1690 et 1725, cette série reste par ailleurs partielle, entrecoupée de nombreux vides dus à l'absence de documentation.

Dans le cas de Piura, le calcul des deux novenos qui représentait $11,1 \%$ du montant de la gruesa selon la règle générale que nous avons énoncée plus haut n'est avéré que pour les années 1600 à 1606 , puis à partir de 1773. Fin 1760, lorsque don Juan Gervacio de Taboada emporta les enchères pour l'ensemble de la dîme de Piura en offrant 20500 pesos pour la biennale 1761-1762, les "deux neuvièmes" qui constituaient le Real Noveno, représentaient alors dans les faits précisément 2121 pesos 4 réaux, soit $10,35 \%$ et non les $11,1 \%$ que supposait la règle générale. Pourtant cette règle semblait appliquée puisque par ailleurs un " neuvième et demi", en réalité 1590 pesos 7 réaux soit 7,76\%, était affecté à la réfection et la fabrication d'églises, et un autre au fonctionnement de l'hôpital de Piura.

De fait, au cours du $18^{\text {ème }}$ siècle, la proportion du noveno real varia entre $10,54 \%, 10,45 \%, 10,35 \%$ et $11,11 \%$ du montant total des affermages. Cette variation est cependant si faible que l'absence d'une information précise sur le rapport entre le noveno et le montant de l'affermage, est de peu d'impact sur la reconstitution même de la série des affermages.

Entre 1760 et 1860, nous avons par ailleurs à notre disposition de manière assez suivie, les cahiers des charges des affermages de la dîme qui détaillent, circonscription par circonscription, les montants de l'affermage sur deux ans et les payements effectués par les fermiers au comissario chargé du recouvrement de ces montants. La combinaison des deux sources d'information nous permet de reconstituer une solide série entre 1725 et 1860 .

En conclusion, si en l'absence de sources il parait impossible de reconstruire une série continue de la dîme pour le $17^{\text {ème }}$ siècle, le $18^{\text {ème }}$ siècle est lui relativement bien documenté, malgré un vide pour les années 1711 à 1725 . Mais - il faut le répéter - les chiffres dont nous disposons ne sont pas les volumes réels récoltés chaque année auprès des producteurs, mais seulement les montants des affermages biennaux. Ces montants nominaux en pesos qui ne reflétaient que les prévisions sur les récoltes, devraient être déflatés avant de permettre des conclusions sur l'évolution réelle de la production régionale tant conjoncturelle que dans la longue durée.

\section{L'ÉVOLUTION DANS LA LONGUE DURÉE DE LA DÎME À PIURA}

Examinons dans un premier temps les traits généraux de l'évolution de la dîme depuis les premières indications, épisodiques, du $17^{\text {ème }}$ siècle jusqu'au données républicaines du milieu du $19^{\text {ème }}$ siècle.

Comme indiqué, les informations sur les montants d'affermage de la dîme de Piura sont pratiquement inexistantes avant la fin du $17^{\mathrm{ème}}$ siècle. Seules sont disponibles quelques années contiguës au tout début du $17^{\mathrm{èm}}$ siècle.

Annotés en pesos de 9 réaux avec les montants du noveno dans les caisses 
royales, la gruesa de la dîme de Piura s'afferma sans grandes variations en moyenne pour environ 1650 pesos entre 1600 et 1607, soit quelques 1850 pesos de 8 réaux.

Il faut ensuite passer à l'année 1645, pour retrouver une mention de la gruesa.

Tableau 2 - Circonscriptions de dîmes dont le noveno était versé dans la caja de Piura au début du $17^{\text {ème }}$ siècle.

\begin{tabular}{|lcccc|}
\hline & \multicolumn{2}{c}{ Ciudad de Piura } & \multicolumn{2}{c|}{ Olmos, Motupe } \\
& Subasta $^{*}$ & Noveno $^{*}$ & Subasta $^{*}$ & Noveno $^{*}$ \\
\hline 1600 & 1610 & $178,, 8$ & 1300 & $144,, 6$ \\
1601 & 1650 & 183,3 & 1700 & 188,8 \\
1602 & 1675 & $188,, 3$ & 1670 & $185,, 5$ \\
1603 & 1701 & 189,0 & 1510 & $167,, 6$ \\
1604 & 1600 & $177,, 7$ & 1550 & $172,, 6$ \\
1605 & 1650 & 183,3 & 1335 & 148,3 \\
1606 & 1650 & 183,3 & 1335 & 148,3 \\
\hline
\end{tabular}

* en pesos,, réaux, peso de 9 réaux. Source : AGI, Contaduria 1862

Nous l'avons vu, Juan Prieto Dávila afferma alors la dîme de la vicaria pour 4220 pesos de 9 réaux soit 4747 pesos et demi de 8 réaux. Quelques années plus tard, en 1653 , ce sont les protocoles de notaires qui nous livrent une autre bribe d'information. Cette année là, Diego de Mogollon engagea exactement la même somme qu'en 1645, 4747 pesos 4 réaux, pour devenir le fermier général des cinq circonscriptions (Archivo Departamental de Piura (ADP). Juan de Morales, leg. 54, 1654, f. 148). Pour 1680, seule la circonscription de Huancabamba manque pour reconstituer le montant total de la dîme de tout le corregimiento : un calcul même très optimiste de l'évolution de la dîme sur cette circonscription absente montrerait que pour cette année, la " gruesa" dépassait légèrement 4000 pesos.

Une autre information sur la gruesa nous est livrée par les caisses royales en 1692 : 6400 pesos coûtait alors au fermier la prise à ferme de la dîme sur une année. En calculant celui des années 1690 et 1691 à partir du noveno, la dîme du début des années 1690 s'arrentait aux alentours de 6000 pesos par an. Quelques années plus tard, sur les trois dernières années du 17 ème siècle, la dîme, qui s'adjugeait à partir de ce temps par biennales, valait à l'année environ 8000 pesos. En cent ans donc, le montant nominal de la dîme de Piura avait été multiplié par 4, avec une croissance apparemment plus forte dans la première moitié du siècle, un ralentissement entre 1653 et 1690, puis une nouvelle accélération dans la dernière décennie du siècle (7). Ce décollage n'est pas pour surprendre, il correspond au développement de l'économie d'élevage de la région, petit bétail destiné à l'industrie du savon sur la côte, mules dans la sierra. Mais

(7) Il faudrait toutefois s'interroger sur l'impact du passage de l'affermage annuel de la dîme à son adjudication par biénnale : la durée n'était-elle pas propice à une augmentation de 
le développement des domaines d'élevage extensif était contrebalancé par la réduction continuelle de la population indienne jusque vers 1650-1660. Une fois les savonneries installées, le plein de bétail fait, la production régionale dut marquer un palier.

Entre 1700 et 1730, le rythme de croissance fléchit. En effet, le montant de l'affermage augmenta de moins de $20 \%$ au cours de cette période (pour la biennale de 1731-1732, il atteignait un premier pic à 21000 pesos). De plus, la dîme, en récession à partir de 1733, revint sur plusieurs années quasiment au niveau du début du siècle.

Tableau 3 - Croissance du montant de l'affermage de la dîme entre 1600 et 1750

\begin{tabular}{|l|c|c|c|c|c|c|}
\hline Années & $1600-1606$ & 1653 & $1690-1692$ & $1700-1706$ & 1725 & $1755-1760$ \\
\hline Montants & 1854 & 4748 & 6035 & 8600 & 9000 & 11550 \\
\hline
\end{tabular}

Début 1741, la dîme était adjugée pour 16400 pesos soit pratiquement la même somme que pour les biennales des années difficiles de la sécheresse du début du $18^{\text {ème }}$ siècle (1705-1710). Selon un cabildo abierto du 19 septembre 1740, l'ensemble du corregimiento de Piura était en crise, les haciendas au plus mal, et le bétail mourrant (9). Mais cette vision apocalyptique devrait être appréciée avec précaution car sa diffusion avait pour intention d'éviter un effort de contribution aux défenses portuaires exigées par le vice-roi alors que s'affirmait la menace d'une expédition anglaise dans les mers du sud. À la même époque, les entrées fiscales du port de Paita diminuaient fortement, mais l'essentiel de cette chute était dû à la diminution des exportations de quinine, plus qu'à celle des produits de l'agriculture et de l'élevage (Schlüpmann, 1993). D'une manière générale cependant, le trafic maritime au nord de la capitale vice-royale s'était fortement ralenti depuis l'espacement des ferias du Panama et le basculement de l'essentiel du mouvement des navires vers le Sud au début du $18^{\text {ème }}$ siècle. Le dépérissement du Panama et les importations massives de blé depuis le Chili à partir de la fin du $17^{\text {ème }}$ siècle affectèrent en tout cas durement toutes les vallées dont les débouchés maritimes furent fortement réduits, de Trujillo jusqu'à Piura.

Après le passage du corsaire Anson qui brûla Paita en 1741, la dîme repartie dans une fulgurante hausse qui se termina avec un sommet à près de 28000 pesos en 1757, pic qui n'allait plus jamais être atteint. Cette hausse qui doubla presque le montant de l'affermage en une quinzaine d'année fut cependant suivi d'un retournement tout

\section{l'affermage?}

(8) Montants moyens par an exprimés en pesos de 8 réaux

(9) “... esta ciudad se alla tan sumamente atrassada en los caudales por los contra tiempos adbersos que se han continuado perdiendose y atrasandosse las haziendas con las mortandades de ganados y cortedad de el precio en que han quedado única expecie con que en otro tiempo han podido adquirir caudales; no pueden desde luego con ningún dinero prompto concurrir para otras plasas pues aun en esta se ha padesido en tiempos mejores la calamidad de ser necesario pedir socorros de jente para defender el Puerto de Payta que en tales ocaciones se mira en ygual peligro como ha susedido biniendo de la ciudad de Loxa compañias a la ayuda y Socorro de esta Plaza y dho Puerto de Payta gastando los besinos la presisa mantención de los que sólo han podido serbir con sus personas y que hallando al presente esta ciudad tan summamente atrasada para poder contribuir cossa alguna y que el Puerto de Payta por ser la garganta de el Reyno necesita de Maior exfuerzo 
aussi impressionnant : la biénnale de 1759-1760 ne s'affermant plus que pour 15840 pesos, le minimum absolu du $18^{\text {ème }}$ siècle ! Cycle éphémère engendré par des marchés particulièrement favorables ou par le développement miraculeux d'une production particulière ? Changement des règles du jeu pour la collecte de la dîme ? Les causes du violent retournement restent à déterminer. La guerre de sept ans qui se déclarait avec l'Angleterre put-elle avoir eu un tel impact sur le versant pacifique du monde ibérique encore marqué par le passage de Anson 20 ans auparavant ? Ou faut-il encore croire le fermier de Santa Ana qui suppliait le commissaire chargé du recouvrement des fermages de lui accorder une baisse sur le montant de 5650 pesos que lui coûta l'adjudication de la biennale en 1759 pour cause de "stérilité " des pâturages (AEP. Causas civiles leg. s/n, 1761-1799) ? Apparemment, la chute de la dîme déjà prise en compte par les fermiers début 1759, fut beaucoup plus sévère que prévue et probablement due à une sécheresse comme nous le verrons ultérieurement.

Dès 1761, la dîme remonta à un niveau qui se situait dans le prolongement d'une croissance plus régulière depuis les années 1730. Cette poussée fut probablement coupée de nouveau par l'aridité qui frappa Piura entre 1767 et le début des années 1780 (10) : la dîme repartit à la baisse, ne parvenant pas à sortir du marasme puisque dans les 15 ans qui suivirent le maximum de 1767-1768, le montant de l'affermage stagna en dessous de 20000 pesos, revenant aux paliers du début du siècle et à un minimum à moins de 17000 pesos pour la fin des années 1770 .

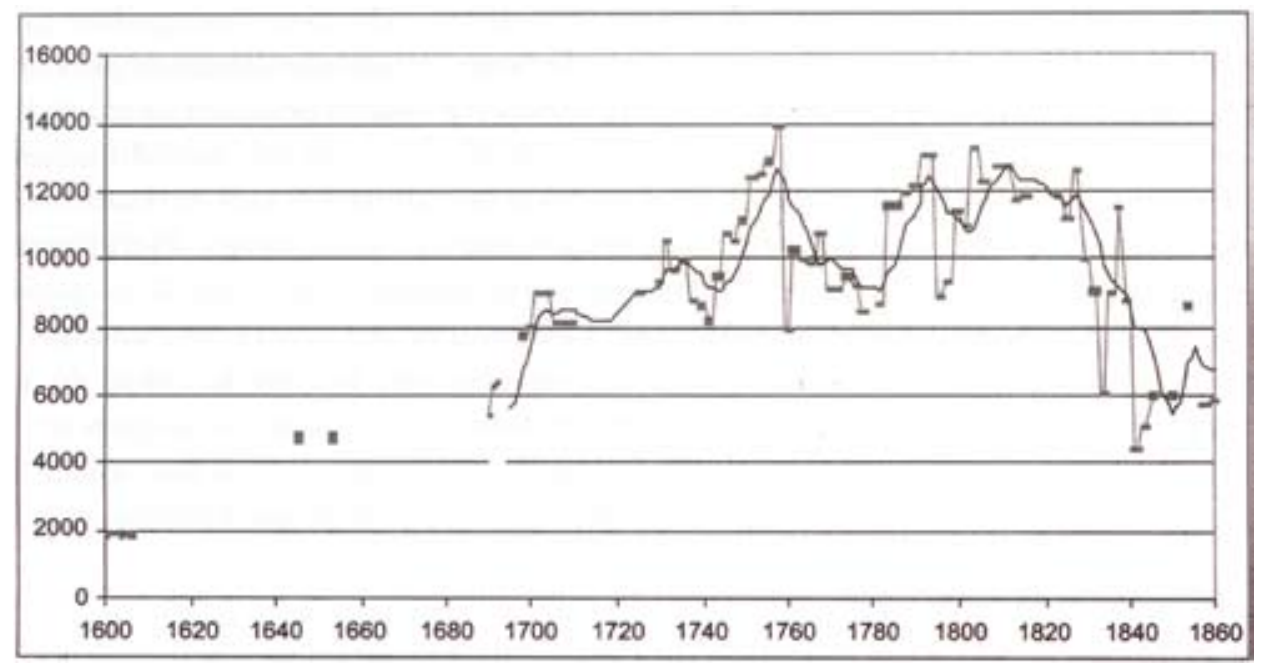

Fig. 2 - Évolution du montant par an et moyenne mobile (10 ans) de l'affermage de la dîme (sources voir annexe).

para su defensa... " p. 60, Libro de Cabildo de Piura, 19-09-1740.

(10) Lors de son séjour à Piura dans la première moitié de 1767, le jésuite Mario Cicala notait déjà une arrivée tardive inhabituelle des eaux du fleuve : "En el año que estuve en Piura, habian pasado siete meses y medio sin que corriera, debido a la acentuada escasez de las lluvias, una sequía en todas las provincias y territorio, que duró hasta comienzos de febrero por lo que no corrió el agua del río Piura: cuando regularmente para diciembre o comienzos de enero y a veces 
À partir de 1785, le corregimiento vécut apparemment une nouvelle période d'embellie qui ramena la dîme de manière moins éphémère au sommet du milieu du $18^{\text {ème }}$ siècle. Certes, la grande sécheresse de la fin du 18ème siècle, grand accroc, ramena les montants d'affermages pendant 2 biennales à 18000 pesos, mais en moyenne entre 1785 et 1805 , ils s'établirent à un niveau supérieur à 23000 pesos. Dans la première décennie du 19ème siècle, ils s'élevèrent même à plus de 25000 pesos. Mais ce fut là la fin d'une augmentation nominale constante de la dîme depuis le début de l'époque coloniale.

À partir de 1829 , le mouvement à la baisse fut sévère et en 1841 , le montant nominal de l'affermage n'atteignait même plus celui de 1653, c'est à dire 8875 pesos pour la biennale 1841-1842, soit 4437 pesos par an. Et si dès la biennale suivante la dîme reprenait une partie du terrain perdu, elle s'établit finalement aux alentours de 6000 pesos seulement par année pour la décennie de 1850 .

Selon ces premières indications - les montants nominaux de l'affermage de toute la dîme de Piura - le niveau soutenu de la production régionale aurait atteint son apogée dans la dernière décennie du $18^{\text {ème }}$ siècle et au début du $19^{\text {ème }}$ siècle (si l'on ne tient pas compte du pic de 1757 et de la sécheresse de 1793-1800). À partir de l'indépendance, à première vue, la valeur de la production agricole et de l'élevage connut une forte réduction et termina au milieu du $19^{\text {ème }}$ siècle à un niveau moitié moindre que celui de la fin du $18^{\text {ème }}$ siècle.

Les montants nominaux de la dîme reflètent-ils pour autant, même si ce n'est que grossièrement, l'évolution de la production agricole ? La multiplication par trois de la dîme dans la première moitié du $17^{\text {ème }}$ siècle, est-elle vraiment le reflet d'une croissance économique de même magnitude ? La production agricole du milieu du $19^{\text {ème }}$ siècle avait-elle réellement baissé au niveau de celle du milieu du $17^{\text {ème }}$ siècle alors même que la population augmentait considérablement depuis le $18^{\text {ème }}$ siècle ? Quels effets auraient sur la courbe un indice des prix qui nous permettrait de déflater la série ? Le tableau serait-il sensiblement modifié, voire bouleversé ?

Malheureusement, nous n'avons pas cet indice des prix pour Piura. Des indices pour d'autres régions du vice-royaume du Pérou semblent indiquer toutefois que la première moitié du $17^{\text {ème }}$ siècle est particulièrement inflationniste : ils doivent nous faire relativiser la croissance de la dîme entre 1600 et 1653 . Indéniable au vu du développement de l'industrie du savon sur la côte, de l'élevage de la mule dans la sierra qui trouvaient un débouché dans des marchés éloignés — Panama, Lima - la production régionale n'a probablement pas été multipliée par 3 alors que la population indigène de Piura continuait parallèlement de chuter jusqu'en 1670 environ.

Pour le $18^{\text {ème }}$ et les premières décennies du $19^{\text {ème }}$ siècles, nous avons très sommairement constitué un indice à partir des prix publiés par P. Macera pour la capitale vice-royale (11). Son application pour une région aussi éloignée que Piura est contestable au vu des débats sur le niveau de l'intégration des marchés du vice-royaume à l'époque coloniale. S'il est donc inutile de s'attarder sur les détails conjoncturels de

desde noviembre, suelen ya correr las primeras aguas".

(11) L'indice a été composé à partir d'un ensemble de données de prix fournis par Pablo 
cette courbe, en revanche, sur le long terme, les montants des affermages corrigés par cet indice des prix liméniens pourraient mieux rendre les grandes tendances " réelles" de la dîme que les données nominales.

À la différence des chiffres nominaux, il faut d'abord constater que les affermages déflatés ne montrent pas de tendance constante à la croissance sur tout le $18^{\text {ème }}$ siècle. Principalement et sans leur attribuer trop d'importance vu l'imprécision de la méthode, les données corrigées suggèrent que l'apogée de l'économie agraire de Piura se situait non pas à la fin mais plutôt au milieu du $18^{\text {ème }}$ siècle. Dès 1760 , la tendance générale

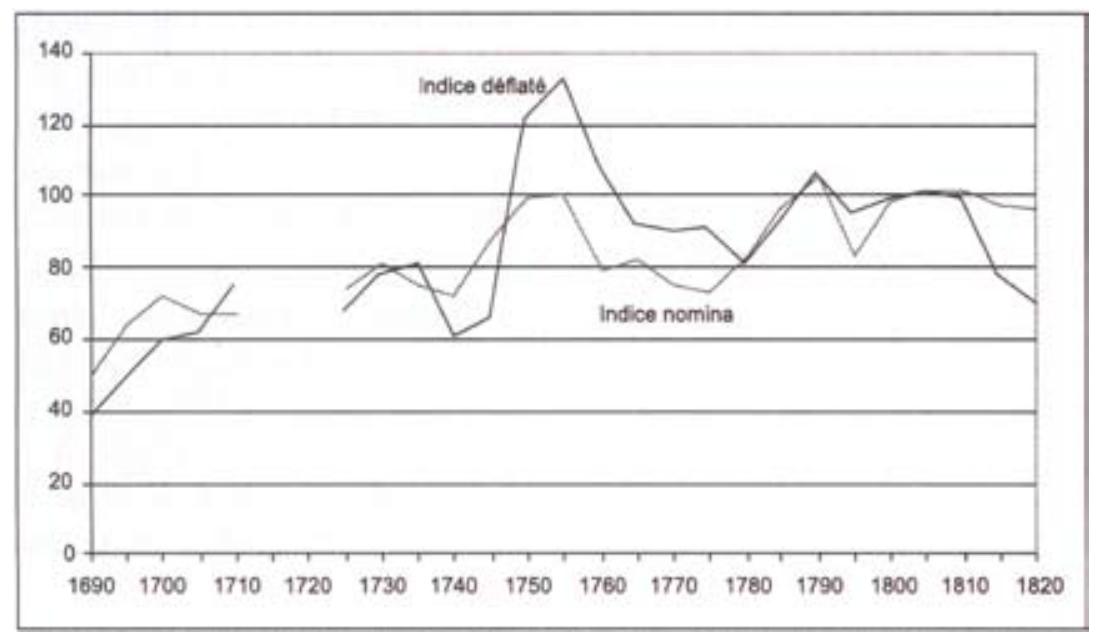

Fig. 3 - Indice nominal et indice déflaté de l'affermage de la dîme de Piura (exprimés par périodes de cinq ans, base 100 = moyenne 1800-1809).

d'une dîme déflatée est en effet clairement orientée à la baisse. Par ailleurs, les affermages corrigés renforcent l'idée d'une stagnation des vallées du nord au début du $18^{\text {ème }}$ siècle après le basculement des principales routes maritimes sur des axes au sud du Callao entre 1710 et 1740 . Ils soulignent aussi l'impact bien plus durable et dévastateur de la première sécheresse de la seconde moitié du $18^{\text {ème }}$ siècle que celle de 1792-1802. Enfin, ils montrent mieux que dès 1810 les revenus décimaux réels s'effondraient littéralement. Ce que soulignerait aussi un indice très rudimentaire des prix du bétail, constitué à partir d'inventaires d'haciendas de Piura indiquant que l'inflation du peso dépassa les $100 \%$ sur la période allant de 1780 à 1860 : son application sur la courbe de la dîme accentuerait encore plus dramatiquement la chute de la première moitié du $19^{\text {ème }}$ siècle, des premières décennies de l'Indépendance.

Les variations du montant global de la dîme ne reflètent cependant pas les évolutions très diverses des différents espaces à l'intérieur de la région. De plus, certaines

Macera pour Lima, les seules à être suffisamment copieuses dans la durée pour en permettre une utilisation de la fin du $17^{\text {ème }}$ au début du $19^{\text {ème }}$ siècle. Simple moyenne des indices raisonnablement étoffés d'une douzaine de produits particulièrement importants dans l'économie de Piura au $18^{\text {ème }}$ siècle (azúcar, trigo, jabón, sal, arroz, garbanzo, frejol, carneros, maíz, bayeta, pabilo, pellejos), l'outil reste très rudimentaire et n'a probablement de signification que pour les très grandes tendances. Voir Pablo Macera, 1992. 
données pour des circonscriptions particulières de Piura sont disponibles dès la fin du $16^{\text {ème }}$ siècle et permettent d'ébaucher une esquisse de l'évolution de la production au $17^{\text {ème }}$ siècle : il paraît donc intéressant de revenir sur les montants des affermages de la dîme pour des circonscriptions particulières de Piura afin de mieux circonscrire les phases de croissance et de stagnation décelées auparavant.

\section{L'ÉVOLUTION DE LA DÎME PAR PERCEPTION}

La première indication pour le corregimiento de Piura d'un montant d'affermage partiel date de l'année 1590, lorsque Juan de Morales, fermier général de la biennale 1589-1590, sous-afferma le partido d'Ayabaca à Pedro de Neyra pour 320 pesos de 8 réaux (ADP. Juan Vaquero, leg. 136, 1590, f. 94). En 1680, la circonscription fut affermée pour 1240 pesos à l'année et en 1711, pour 5200 pesos sur deux années. En 121 ans, le niveau de la dîme de cette région de montagne se multiplia donc par 16 .

En 1636, le fermier général, don Pedro de Balladares prit en sous-ferme la perception de la dîme de Huancabamba, Sondor, Sondorillo et Huarmaca au capitaine Juan Cortes Carrasco pour 710 pesos. En 1716, don Joseph Venegas Machuca afferma la dîme de la-dite circonscription à l'année pour 1800 pesos. Dans ce cas, la valeur de la production de l'agriculture et de l'élevage aurait été multipliée par 2,5 seulement en 80 ans.

La perception de la dîme de la circonscription du Chira et de Tumbes fut adjugée pour 850 pesos en 1658. En 1662, ce chiffre descendit à 810 pesos et en 1680, à 800 pesos. Une trentaine d'années plus tard, en 1711, la dîme annuelle de ce même partido, s'éleva à 1700 pesos. Entre 1680 et 1711, elle se multipliait donc par deux alors qu'elle avait stagné après le milieu du $17^{\text {ème }}$ siècle.

Analysée sur les cinq circonscriptions, la brusque accélération de la croissance aurait eut lieu au cours des dernières décennies du $17^{\text {ème }}$ siècle, mais à partir de la première décennie du $18^{\text {ème }}$ siècle, cette expansion ralentissait. Au vu des rares données disponibles, une première supputation délimiterait deux périodes : d'abord une longue croissance soutenue entre la fin du $16^{\text {ème }}$ siècle et la seconde moitié du $17^{\text {ème }}$ siècle, puis une période de croissance exceptionnelle dans les dernières décennies du $17^{\text {ème }}$ siècle. Dans l'ensemble, l'évolution de la dîme dans les différentes provinces de Piura souligne encore que le $17^{\text {ème }}$ siècle fut bien un siècle de croissance généralisée pour l'ensemble de la région : à cette époque, les circonscriptions de la sierra, semblaient toutefois les plus favorisées.

Pour toute la première moitié du $18^{\text {ème }}$ siècle, les informations restent toujours très partielles. Selon ces données, la sierra, légèrement mieux documentée, semble freiner sa croissance à partir de la fin du $17^{\text {ème }}$ et du début du $18^{\text {ème }}$ siècle. Dans le cas de Huancabamba, ce sont des sommes du même ordre que recueillit le Chapitre entre 1716 et 1737-1738. Le partido de Ayabaca, s'affermait pour les mêmes montants en 1739-1740 qu'au début du $18^{\text {ème }}$ siècle : 5200 pesos.

Indubitablement, c'est au cours de cette période que les vallées de la côte revinrent sur les régions de montagne. Bien inférieurs encore au début du $18^{\text {ème }}$ siècle, les affermages de la dîme du Chira et du Piura allèrent se retrouver à égalité avec, voire dépasser, Ayabaca et Huancabamba au milieu du $18^{\text {ème }}$ siècle. 
La circonscription de Santa Ana — en gros la vallée du Haut-Piura — fut adjugée pour 400 pesos en 1680,300 pesos en 1688 . Pour 1744-1745, juste après la crise de la fin des années 1730, le montant de l'affermage biennal en récupération s'élevait à 3838 pesos. Dix ans plus tard, en 1753, il dépassait 6000 pesos : en somme, au cours de la première moitié du $18^{\text {ème }}$ siècle, la dîme de Santa Ana aurait au moins été multipliée par 5 ou 6 ! Dans le cas de la vallée du Chira, l'accroissement entre 1711 et 1753, fut lui aussi marqué, puisque la dîme ne fut pas loin de doubler en 40 ans environ.

Après la grande récession de 1759 , les quatre grands partidos se retrouvèrent tous au même niveau, affermés entre 4700 et 4850 pesos vers 1762. Mais la poursuite, voire le regain de l'aridité jusqu'à la fin des années 1770, en différencia le développement ultérieur. Alors que la côte et la région de Huancabamba semblaient souffrir de la même manière de la sécheresse, Ayabaca se maintint aux niveaux de 1763-1764. Avec le retour d'une période plus humide, ce furent surtout les vallées du Piura et du Chira qui enregistrèrent une augmentation extraordinaire de leur dîme, qui doubla en dix années seulement. Leur chute avec la sécheresse de la dernière décennie du $18^{\text {ème }}$ siècle n'en fut que plus brutale et souligne que les grandes variations de la dîme dans son

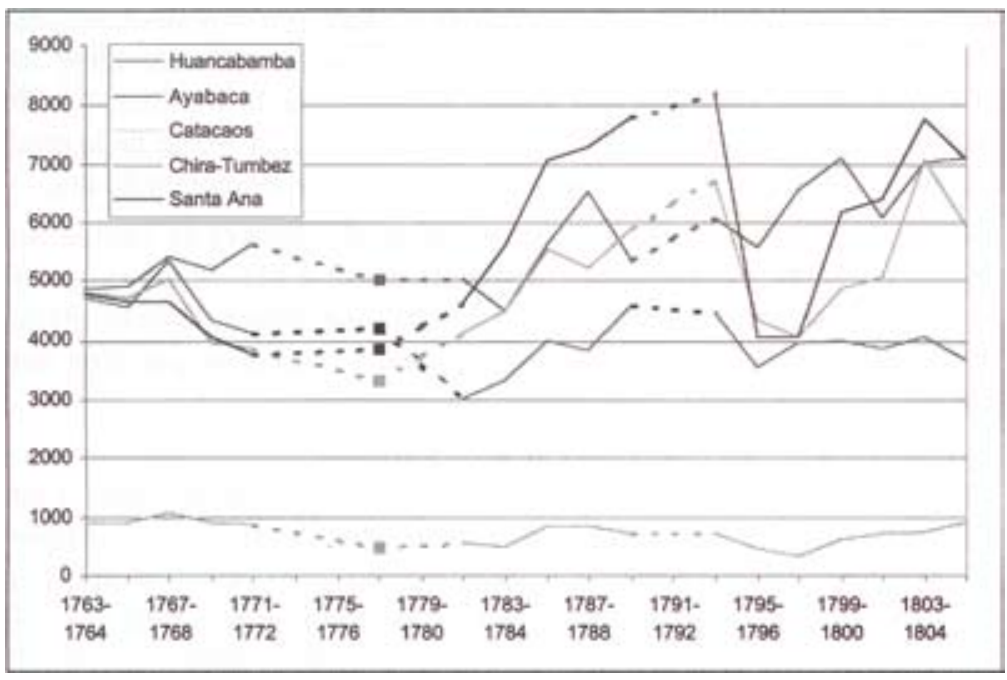

Fig. 4 - Évolution des montants des affermages de la dîme de Piura par partido, 17631806 (sources : voir annexe).

ensemble furent essentiellement dues à la sensibilité des régions côtières au manque d'eau. Ayabaca, malgré un petit accroc en 1795-1796 repartait en effet à la hausse dès 1797. De même, Huancabamba qui ne s'était guère développé après les difficiles années 1770 , chutait seulement de $20 \%$ environ et se rétablissait aussi dès 1797 à un niveau autour de 4000 pesos.

Mais sur l'ensemble de la seconde moitié du $18^{\text {ème }}$ siècle, les circonscriptions de Huancabamba et Catacaos furent les plus défavorisées dans leur développement. Le partido de Huancabamba semblait même en franche régression depuis le pic de 1753, non loin de diviser par deux l'affermage de sa dîme. Un possible réaménagement 
des circonscriptions ecclésiastiques et donc de la zone de recouvrement de la dîme au profit de Ayabaca vers 1780 aurait-il été responsable de l'apparent déclin de cette zone de la sierra ? À l'inverse, d'après les montants nominaux au moins, au début du 19 ème siècle, Ayabaca, Santa Ana et le Chira avaient tous reprit près de 30\% sur les fermages des années 1760.

L'inflation généralisée qui s'empara du peso dès la fin de l'époque coloniale, doit cependant nous rendre prudent quant à une interprétation littérale de ces chiffres : car ces $30 \%$ de croissance ne sont guère supérieurs à l'augmentation de la valeur nominale du bétail sur les grands domaines de Piura au cours de la même époque. Avec cette inflation probable (mais qui reste à confirmer par un indice de prix plus solide) la stagnation de la dîme confirmerait une sorte de léthargie générale du corregimiento de Piura sur la fin de la période coloniale, morosité confirmée parallèlement par la progressive disparition des grandes savonneries qui s'étaient installées sur les berges du Piura au $17^{\text {ème }}$ siècle.

Pour le restant du $19^{\text {ème }}$ siècle, les montants par partido nous font malheureusement défaut. Sur l'ensemble de Piura, entre 1803-1804 et 1827-1828, le montant de l'affermage de la dîme par biennale plafonnait à 26000 pesos. Puis, il s'écroula dans la décennie de 1830, et malgré un sursaut entre 1835 et 1840, se stabilisa alors autour de 12000 pesos seulement. Selon les montants partiels des affermages en 1855, unique année pour laquelle nous ayons ces informations et encore incomplètes puisqu'il y manque le montant pour Ayabaca, les circonscriptions auraient toutes été affectées dans les mêmes proportions : l'Indépendance du Pérou, et l'avènement des nations latino-américaines désorganisant les circuits commerciaux, il est possible que la diminution des montants d'affermage fut beaucoup plus la conséquence de la contraction des marchés qu'une chute de rare ampleur de la production agricole et de l'élevage, au moment même où la population de Piura augmentait considérablement.

Tableau 4 - La dîme par circonscription entre 1680 et 1823 (12).

\begin{tabular}{|lccccccccccc|}
\hline Année & \multicolumn{2}{c}{1680} & \multicolumn{2}{c}{1711} & \multicolumn{2}{c}{1763} & \multicolumn{2}{c}{1793} & \multicolumn{2}{c|}{1823} \\
& Montant & $\%$ & Montant & $\%$ & Montant & $\%$ & Montant & $\%$ & Montant & $\%$ \\
\hline Huancabamba & $1184^{a}$ & 29 & - & - & 2350 & 24 & 2222 & 17 & 1750 & 15 \\
Ayabaca & 1240 & 30 & 2600 & - & 2425 & 24 & 3030 & 23 & 2100 & 18 \\
Catacaos & 500 & 12 & - & - & 454 & 5 & 354 & 3 & 325 & 3 \\
Chira-Tumbes & 800 & 19 & 1700 & - & 2400 & 24 & 3358 & 26 & 3500 & 30 \\
Santa Ana & 400 & 10 & - & - & 2375 & 24 & 4090 & 31 & 4150 & 35 \\
Total & 4124 & 100 & - & - & 10000 & 100 & 13044 & 100 & 11825 & 100 \\
\hline
\end{tabular}

${ }^{a}$ calculé en fonction du taux moyen de croissance entre 1636 et 1716 (sources : voir an-

(12) Années choisies pour lesquelles des informations sur au moins deux circonscriptions sont disponibles : 1680, 1711, 1763, 1823. L'année 1793 se plaçant au milieu de l'intervalle 1763-1823, pour la période où les données sont continues. 
Pour résumer, les circonscriptions de la sierra de Piura furent les premières à se développer significativement au $17^{\text {ème }}$ siècle. En 1680, l'examen de la répartition des montants d'affermage nous montre que les circonscriptions de Huancabamba et Ayabaca constituaient près de $60 \%$ du montant total de la dîme, alors que les vallées de la côte ne représentaient que $40 \%$ de cette somme. À cette époque, la production de la circonscription de Catacaos, essentiellement peuplée d'Indiens constituait encore 12 $\%$ du montant global de la dîme et celle des vallées du Chira, du Moyen et Haut-Piura seulement la moitié des dîmes de la Sierra. Au milieu du $18^{\text {ème }}$ siècle, les circonscriptions de Huancabamba, Ayabaca, Chira et Santa Ana se partageaient à part égale la presque totalité de la dîme, alors que la contribution de Catacaos restait la même depuis le $17^{\text {ème }}$ siècle et proportionnellement ne représentait plus que $5 \%$ du montant total de la dîme. Un demi-siècle plus tard, en 1823, les rapports de 1680 s'étaient inversés : l'importance de la production agricole et d'élevage des vallées du Chira et du Piura était devenue deux fois plus importante que celle de Huancabamba et Ayabaca.

Pendant les deux premiers siècles de l'époque coloniale, les régions de montagne de Piura furent donc les premières à bénéficier de l'élevage extensif et d'une reconquête de la frontière agricole. Mais cette tendance s'inversa à partir de la seconde moitié du $18^{\text {mèe }}$ siècle, quand les vallées de la côte eurent surmonté la terrible chute démographique et la perte des systèmes d'irrigations pré-coloniaux.

\section{LA DÎME COMME INDICATEUR DE LA CONJONCTURE AGRICOLE ET D'ÉVÉNEMENTS CLIMATIQUES}

Au-delà des grands mouvements, la dîme nous permet-elle de déceler la conjoncture agraire sur le court terme à Piura? Nous permet-elle de découvrir les problèmes de production? Avant le $18^{\text {ème }}$ siècle, l'exercice s'avère impossible en raison des absences répétitives de sources. Voyons donc, par contre-épreuve, de quelle manière des moments de crise connus se répercutèrent et de quelle manière sur les montants d'affermage de la dîme entre 1700 et 1860, époque pour laquelle la série décimale est relativement complète et pour laquelle nous avons une chronologie plus détaillée des oscillations climatiques du Pacifique sud (13).

Plusieurs sources confirment une sécheresse particulièrement durable dès le début du $18^{\text {ème }}$ siècle. En novembre 1705, un débat au sein du cabildo de Piura sur l'affermage de la sisa et l'approvisionnement en viande de la ville informe indirectement que l'eau manquait sévèrement depuis 4 ans et ce particulièrement sur la côte (14). En 1709, le fermier de l'alcabala dénonçait l'irrationalité du montant de l'affermage, vu l'état du commerce de la région sinistrée par la sécheresse qui durait depuis 10 ans (15). Et encore en 1722, Maria Leonarda de Sojo Cantoral, fermière de l'hacienda Malingas depuis l'année 1710 affirmait avoir reçu le domaine à une époque de grande sécheresse qui causa la mort de nombreuses têtes de bétail (AGNP. Real Audiencia, leg. 45 , cuad. 286, 1722. “ en tiempos esterilísimos por cuia causa avía mucha mortandad

(13) Voir en particulier les travaux menés par Anne Marie Hocquenghem et Luc Ortlieb sur la révision de la chronologie des évènements El Niño sur la côte péruvienne dont les interrogations ontinspirés cette recherche (Hocquenghem \& Ortlieb, 1992 ; Hocquenghem, 1998)

(14) ALMRE, PIV 1, caja 446. Libro de cabildo que corre desde primero de 1705 hasta mayo 
de ganados").

Que nous disent les montants de l'affermage de la dîme ? Jusqu'à la biennale de 1701-1702, ils sont en franche augmentation. Début 1703, alors que la sécheresse semble déjà installée depuis plus d'une année, la dîme est cependant encore une fois adjugée à 18000 pesos, la même somme que deux années auparavant. Ce n'est finalement qu'en 1704, que les fermiers tiendront apparemment compte de la sévérité du manque d'eau en abaissant l'affermage à 16200 pesos, montant qui se maintiendra à ce niveau au cours des années suivantes jusqu'aux enchères de 1708. Après cette date nous n'avons malheureusement pas de données qui permettraient d'évaluer l'impact de l'aggravation de la sécheresse sur la dîme.

Pas de chiffres non plus sur la dîme pour l'année 1718, année d'inondations qui détruisirent entre autres la savonnerie de Antonio Bernaldo de Quiroz située sur les berges du Río Piura.

En 1728, l'un des plus grands déluges que connut la région au cours de l'époque coloniale ne sembla toutefois pas avoir d'impact marqué sur la dîme puisqu'elle fut adjugée cette même année pour un montant légèrement supérieur à celui de 1725-1726 (l'information pour la biennale 1727-1728 étant absente). Ces premiers exemples de l'effet des variations climatiques sur la dîme soulignent ainsi ce que nous avions déjà pu noter précédemment : ce furent surtout les sécheresses prolongées qui affectèrent durablement l'économie coloniale de Piura et furent relevées par les contemporains.

de 1706... “ El señor capitan don Francisco Hozes y Espinoza dijo que tiene entendido que la falta de aguas de cuatro años a esta parte a sido causa de la esterilidad de pastos de que se padese hasta el dia de hoy por cuya causa han peresido los ganados obejunos mas que le consta que los mas hacendados que tienen obligación de dar el abasto se han proveido de algunas obejas y cantidad de carneros que han embiado a comprar a las serranías... », «El señor capitan don Lorenzo Lopez de Padilla que es verdad que a cuatro años que no lluebe... " (02-11-1705).

(15) AGNP, C7 Cajas Reales Piura, leg. 1205, cuad. 20, 1709. " En la ciudad de San Miguel de Piura en catorse dias del mes de septiembre de 1709 años sus mercedes los señores juezes ofiziales de la real hazienda de ella thesorero don lazaro Guerrero y contador don Ysidro Jaime de los Rios = vistos estos autos y que de ellos consta haver provado con vastante numero de testigos don Jazinto de Urdanigui la esterilidad que havido de diez años a esta parte en esta provincia falta de comercio $y$ de vecinos por cuyas razones a benido a menos cavo el real derecho de alcabalas..", "La segunda, la esterilidad de frutos por que naciendo de estos la abundancia de los tratos, mientras mas fueren los unos han de ser mas continuos los otros, y asimismo mas crecidos con que nesesariamente han de acresentar los derechos reales y haviendose provado la esterilidad que se ha padecido en dha ciudad de Piura y su jurisdiccion por la desgracia y calamidad de los tiempos presentes com tan bien se ha padecido y padece en todos los valles de la jurisdiccion de esta ciudad, llegandose asimismo a los de dha ciudad de Piura por estar vezinos al mar y ser de una misma naturaleza, se manifiesta con evidencia el conocido agravio que hizieron los dichos Oficiales Reales en condenar a dho Jazinto de Urdanegui en los dhos mill y cinquenta pesos en cada un año= La tersera sircunstancia consiste en haver havido mucha mortandad de ganados, como lo deponen contestemente los testigos todos ; y siendo esta especie el principalissimo efecto de que en aquella jurisdiccion se puede satisfacer el ramo de la alcabala por ser el mas frequente comercio que tienen las personas de aquel districto haviendo sido muy pocos los tratos de mui corto ganado por el mucho que se a muerto no puede haver rendido para pagar los dhos mill y cinquenta pesos".

(16) Courbes des montants en pesos des affermages par biennales et de la moyenne mobile 
Le retournement de 1737 en est une autre illustration. Affermée pour 20000 pesos en 1735, la dîme tombait à 17600 pesos en 1737. Une fois encore, un petit commentaire de l'époque indiquant qu'en 1735 le bétail sur l'hacienda de Locuto mourait en raison de la "stérilité des pâturages" (ADP. Causas ordinarias, leg. 26, exp. 539, 1735), nous met sur la piste de la sécheresse. Détail qui corroborerait les informations du cabildo de Piura en 1740 sur l'état catastrophique du corregimiento dont nous avons déjà fait état.

Inversement, la forte augmentation continue de la dîme jusqu'en 1757 exclurait d'autres périodes de " stérilité " après la crise de la fin des années 1730, ce qui est validé par l'absence d'information " qualitative" dans ce sens entre 1740 et 1760 . Les seules informations climatiques exceptionnelles rencontrées pour cette période font état de pluies d'envergures au cours des années 1747-1748, années du seul accroc d'ailleurs dans cette croissance unique des revenus décimaux. Ces quinze années suffisamment humides pour exclure une quelconque mention de sécheresse, furent indubitablement les plus belles du corregimiento de Piura à l'époque coloniale.

En 1759, la dîme de Piura subissait la plus importante baisse de son histoire avant l'Indépendance. Et cette fois-ci encore, de sécheresse il faut parler. En est témoin le fermier de la dîme de Santa Ana, le partido de la vallée du Piura généralement le plus affecté par les périodes d'aridité. En 1760, ce fermier tenta de faire réviser le montant de l'affermage qu'il avait contracté pour la biennale de 1759-1760, en raison expliquaitil " du manque notoire de pâturages". Il indiquait ainsi que "les troupeaux [de petit bétail] qui normalement donnaient cent quintaux de graisse, en produisaient seulement soixante... " et que “... le sucre que ladite hacienda [de Yapatera] pourrait donner sur

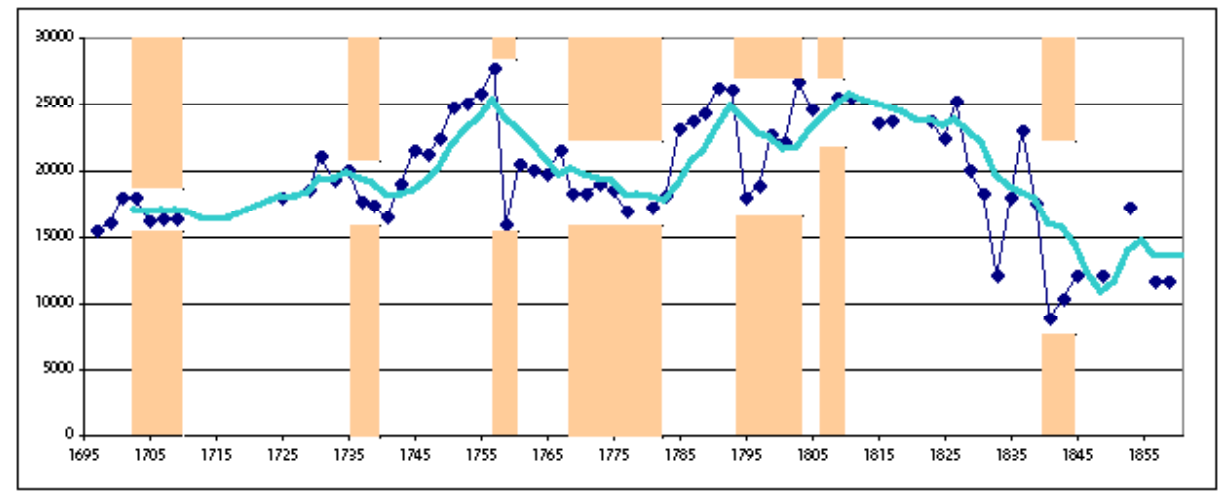

Fig. 5 - Évolution de la dîme et sécheresses à Piura, 1697-1859 (Les périodes de sécheresses sont indiquées par les zones hachurées) (16).

les deux années est jugé atteindre à peine le nombre de douze arrobes... ". Au total, il affirmait que l'ensemble de la dîme récoltée s'élevait à 5291 pesos seulement sur les deux années, alors que le partido avait été affermé pour 5650 pesos (17).

Après une légère reprise de 1761 à 1764 , une nouvelle période sèche se dessina

sur 5 affermages.

(17) AEP, Epoca colonial, causas civiles, legajo 2, 1761-1788, exp. sin num. Dans une affaire 
entre 1766 et 1776 : selon don Juan José Carrasco, propriétaire de l'hacienda Congoña située dans les montagnes de Huarmaca, l'eau avait manqué à tel point entre 1766 et 1768, qu'il n'avait que rarement put faire fonctionner son moulin à farine (ADP. Cor. c. ord. leg. 34, exp. 717, 1766, f. 94vta.). D'après la production de blé de l'hacienda, cette sécheresse sévit surtout au cours des années 1767 et 1768, et semblait moins aiguë à partir de 1770. Quelques années plus tard cependant, en 1776, don Manuel Farfan de los Godos affirmait qu'une longue période sans eau avait causé le décès de l'ensemble du bétail de son hacienda Suyo dans la basse vallée du Quiroz. Entre 1768, date à laquelle il avait reçu l'hacienda de son père et 1776, date à laquelle il l'avait revendue, l'hacienda avait perdu la moitié de sa valeur (18). De même, en décembre 1774, le cabildo de Piura qui avait pris la décision de remettre en état le barrage sur le Río Piura notait la " falta de agua, pues cada año va en aumento la escasez.. "(García Rossel, 1903).

Début 1767, lorsque fut affermée la dîme de la biennale de 1767-1768, le regain de sécheresse n'impressionnait pas encore les fermiers puisque le montant de l'affermage était en hausse par rapport à la biennale précédente : 21574 pesos après le minima de 19550 pesos de l'année précédente. Mais deux années plus tard, en 1769, la dîme plongeait à quelques 18000 pesos et se maintint à ces niveaux pendant une dizaine d'années avant de tomber encore en 1777, lorsque les fermiers n'offrirent plus que 16975 pesos pour la biennale 1777-1778. En 1779-1780, une première mise au enchère de la dîme fut annulée.

À défaut de plus ample information, l'absence de pluie qui avait décimé le bétail de l'hacienda de Suyo affecta la dîme jusqu'à la fin 1784 au moins lorsque s'effectua la "subasta" de la biennale 1784-1785. Des pluies importantes semblent avoir touché le nord du Pérou et Guayaquil en 1784-1785, il n'est donc pas surprenant que les fermiers spéculaient sur une hausse des rentrées de la dîme. Les enchères atteignirent ainsi plus de 23000 pesos cette année-là contre un peu plus de 18000 pesos en 1782 .

En somme, il apparaît qu'une longue période aride affecta Piura entre 1766 et le début des années 1780 . Étendu à la sécheresse aiguë de 1757, cette période au cours de laquelle aucune mention de pluies importantes n'a pu être retrouvée, a probablement définitivement affaibli une économie coloniale basée sur l'élevage de petit bétail et la confection de savon : la longue dépression de la dîme dans un contexte d'une population en nette croissance en fait clairement état.

Mais cette grave crise de la seconde moitié du $18^{\text {ème }}$ siècle a été éclipsée par la reprise des années 1780, par la grande inondation de 1791 et par la sécheresse de la fin

concernant l'hacienda de Sancor, l'une des parties indiquait qu'une sécheresse sévissait dès 1757 ! AGNP, Real Audiencia, causas civiles, leg. 319, cuad. 2909, 1793.

(18) ADP. Escribanos. Alcaldes ordinarios, leg. 150, 1776, f. 35 : “ y porque con la esterilidad de los tiempos con la falta de aguas y escases de pastos que en los años pasados se ha experimentado en esta provincia se hallan en deplorable estado todas las haciendas de ella, y con especialidad la citada de Suyo que se le han muerto todos los ganados, y consumido todos los muebles y herramientas con que la recivi y me la entrego el referido mi padre de modo que solo ha quedado en tierras y casco limpio de hacienda sin aperos algunos de modo que se me ha imposibilitado el pagar los reditos de los censos principales sobre ella..."

(19) Biblioteca Nacional del Perú (BNP). Ms. Cronológico, 1798, C4238 : «... asendió su 
du $18^{\text {ème }}$ siècle bien mieux mises en relief par les descriptions du corregimiento de la fin de l'époque coloniale. Cette sécheresse de plus de 10 ans — de 1792 à 1802 — fut, elle aussi, une catastrophe pour l'ensemble des haciendas d'élevage et porta le coup fatal à la principale industrie régionale déjà amoindrie : “...les pluies sont aléatoires, et si elles se répètent sur une, deux ou trois années, elles viennent à manquer pendant huit, neuf ou même onze années comme cela s'est vu depuis [mille sept cent] quatre-vingtonze jusqu'à cette année passée de [mille] huit cent deux " indiquait ainsi l'hacendado Helguero dans l'une des ces “informaciones geógraficas" que réclamait la couronne pour tout le Pérou (Helguero, 1984[1802-1803] : 9).

Quel fut l'impact de cette grande sécheresse sur les montants de la dîme ? Pour la biennale 1793-1794 — les enchères s'étant tenues en mars de l'année 1793 - la dîme semblait encore tenir compte du bénéfice des pluies diluviennes de 1791 et le montant total de son affermage dépassait 26000 pesos : un deuxième sommet pour l'époque coloniale. Pour les biennales 1795-1796 et 1797-1798 cependant, la sécheresse s'ancrait dans les esprits, puisque les fermiers n'offrirent pas plus de 18000 pesos sur l'ensemble de la région. D'après des appréciations contemporaines, la sécheresse affecta même les zones reculées de la Sierra : une bonne partie du bétail de l'hacienda Samanga - située sur le río Calvas, aux confins de la province d'Ayabaca - fut décimée entre 1789 et 1798, réduisant de $20 \%$ la valeur de l'hacienda (19). Pourtant, si les courbes de l'évolution de l'affermage de la dîme par partido accusent effectivement un fléchissement initial général avec la biennale de 1795-1796, dans la sierra, dès 1797 , les fermiers révisaient déjà à la hausse les revenus potentiels de la dîme. Mais cette hausse est-elle due à une augmentation de la production où à une valorisation des cultures, une inflation des prix des récoltes de la sierra qui compensaient les manques de la côte ? Assez vite d'ailleurs, sur la côte aussi, alors que la sécheresse sévissait encore, les montants d'affermages repartirent à la hausse : en l'absence de données plus détaillées sur l'état des haciendas du Chira et du Haut-Piura, cette hausse pourraient avoir comme cause l'enchérissement de la faible production restante plus qu'un accroissement productif.

Malgré les deux années pluvieuses de 1803 et 1804 (Eguiguren, 1894), une nouvelle sécheresse s'abattit sur Piura au début du $19^{\text {ème }}$ siècle et se poursuivit jusqu'en 1814. Les éleveurs de petit bétail rechignaient même à payer l'impôt sur les rares ventes de viande d'ovins et caprins. Un important éleveur de la région, Francisco Menendez Pabon indiquait n'avoir abattu qu'un seul et maigre troupeau de petit bétail en 1814 (selon Aldana, 1989 : 97, 102), année au cours de laquelle Piura fut d'ailleurs affectée par un terrible tremblement de terre qui laissa la ville en ruine (20). Sur l'affermage de la dîme cependant, cette sécheresse n'eut pas d'impact particulièrement marqué, la “ gruesa " continuant d'être enchérie à des sommes atteignant 25000 pesos. Dès 1819 ,

valor a la cantidad de 28000 pesos, hallandose entonces dicha hacienda [Samanga] con mejores entables de caña dulse, y gran numero de ganados mayores de toda especie, los quales estan hoy disminuidos por la general mortandad y escases que se experimentan en todas las haziendas. Por cuyo motivo considera el declarante que la hazienda esta bien pagada en la cantidad de 23000 pesos que ofrese el regidor don José Lopez por ella...»

(20) “ La ciudad de San Miguel de este nombre [Piura] es la capital que acaba de padecer 
d'importantes pluies tombèrent sur la région, puisque en avril 1820, le curé de Lancones dans le Chira émettait une supplique pour refonder l'église de l'annexe ruinée par les eaux "abondantes" de l'année antérieure (21). Néanmoins, vers cette époque alors que le corregimiento semblait bénéficier de deux décennies particulièrement humides, un long déclin structurel s'amorçait.

Deux fois encore, dans cette première moitié du $19^{\text {ème }}$ siècle, la courbe de la dîme se cassait brutalement : au cours de la période 1829-1833 et entre 1839-1841. Mais apparemment, seule la deuxième chute correspondait à une nouvelle sécheresse qui sévit à Piura entre 1837 et 1841 , la première se plaçant tant avant qu'après les importantes inondations de 1828. Ces inondations aggravèrent-elles la chute d'une dîme déjà malmenée par les incertitudes politiques des premières années de l'Indépendance ? Cela reste à démontrer.

Dans l'ensemble, le bilan est nuancé : entre 1700 et 1850 , les montants de l'affermage de la dîme reflètent dans une certaine mesure les accidents climatiques et donc les problèmes de production qui affectèrent la région. Quatre retournements dans les revenus décimaux révèlent effectivement quatre périodes de sécheresse au cours du $18^{\text {ème }}$ siècle mais n'en marquent pas précisément les limites : en l'absence d'un indice des prix régionaux, on ne peut que deviner les effets d'une production raréfiée et de la spéculation sur les montants de la dîme par exemple pour la sécheresse de 1792 à 1802, dont le terme peu évident sur la courbe est mieux détaillé par d'autres sources. L'alternance de périodes sèches et époques plus humides semble donc être ce que la série des affermages de la dîme rend le mieux pour Piura, mais cela seulement jusqu'à la fin de l'époque coloniale dans un environnement administratif et politique relativement stable.

S'il est possible d'utiliser les séries décimales comme indicateurs de la variabilité de la production régionale lorsque les sources sont abondantes et suivies, en revanche, dans le cas de Piura, l'absence de données continues rend malheureusement l'exercice impossible pour le $17^{\text {ème }}$ siècle. Quant à quantifier directement l'évolution en volume de la production régionale... seul un indice détaillé des prix locaux le permettrait. Celui-ci est-il possible pour la région à l'époque coloniale ? Rien n'est moins sûr, là encore en raison de l'absence de sources sérielles.

Cette approche un peu pointilleuse des mécanismes de constitution des séries décimales montre en tout cas, encore une fois, l'extrême circonspection qu'il importe d'observer avant d'interpréter les fluctuations des divers indicateurs de la dîme en conjoncture agraire ou de traduire, même grossièrement, les montants d'affermage en niveau de production.

Cependant, au-delà de la conjoncture, cette analyse des revenus décimaux de Piura permet néanmoins de délimiter les grandes tendances qui marquèrent la région

grande ruina en sus edificios con el terrible terremoto que se experimento en la mañana del dia primero de febrero del año presente [1814] ". ALMRE, LEA 12-52, 1814.

(21) AEP. Causas civiles, leg. 13, exp. 185, 22-4-1820. “ que la capilla publica de la hacienda de Lancones anexo de esta matriz se ha arruinado por el todo con las abundantes aguas del año proximo pasado de manera que es preciso reedificarla de nuevo desde sus cimientos... ", f. 2. 
au cours de l'époque coloniale. Après un quadruplement des montants de la dîme entre le début et la fin du $17^{\mathrm{ème}}$ siècle, et tout en marquant un palier dans la croissance entre 1710 et 1730 , ce fut dès le milieu du $18^{\text {ème }}$ siècle que cette société agraire atteint son apogée sur des équilibres instaurés un siècle plus tôt : dès la fin de la décennie de 1750 , en dépit de quelques rebonds, les revenus réels de la dîme s'orientaient définitivement à la baisse. Le regain général des vallées du Nord du Pérou dans la seconde moitié du $18^{\text {ème }}$ siècle, soutenu par la réactivation du trafic maritime entre le Callao et Guayaquil — boom du cacao — ne bénéficia ainsi qu'un court moment au corregimiento de Piura frappé sévèrement par la longue sécheresse de 1760-1770. Malgré une reprise entre 1785 et 1792, la seconde sécheresse de la fin du siècle, plus courte pourtant, porta le coup de grâce à l'élevage extensif du petit bétail et à l'industrie du savon, entraînant tôt la région dans un marasme général avant sa reconversion dans le coton au milieu du $19^{\text {ème }}$ siècle.

Reste à savoir si le parcours de Piura fut exceptionnel ou s'il s'inscrivait dans une conjoncture régionale voire continentale plus large ? Pour le préciser et être en mesure de renouveler le débat sur les grandes tendances économiques du vice-royaume péruvien à partir de bases solides, il conviendrait de développer ou de construire avec une même précaution des séries décimales sur les provinces voisines de Loja, Cajamarca, Lambayeque et Trujillo ainsi que de les confronter à des séries de prix plus élaborées.

\section{Références citées}

ALDANA, S., 1989 - Empresas coloniales. Las tinas de jabón en Piura, 194p.; Lima: CIPCA-IFEA.

GUERRERO SORIANO, C, P., 1994 - Producción, evolución económica y análisis decimal. Un Estudio sobre el Río de la Plata en el siglo XVIII. In: Anuario de Estudios Americanos, Tomo LI, núm. 1: 91-122.

CARMAGNANI, M., 1973 - Les mécanismes de la vie économique dans une société coloniale. Le Chili (1680-1830), 392p.; Paris : SEVPEN.

CERVANTES BELLO, F. J., 1999 - Crisis agrícola y guerra de Independencia en el entorno de Puebla. El caso de San Martín y sus cercanías, 1800-1820. Estudios de Historia Novohispana, Vol. 20: 108-133.

CICALA, M., 1994 - Descripción Histórico-topográfica de la Provincia de Quito de la Compañia de Jesús, 669p.; Quito: Biblioteca Ecuatoriana "Aurelio Espinosa Polit" - Instituto Geográfico Militar.

COATSWORTH, J. \& NEWLAND, C., 2000 - Crecimiento Económico en el Espacio Peruano 1681-1800: una visión a partir de la agricultura. Revista de Historia Económica, 18(2): 377-391; Madrid.

EGUIGUREN, V., 1894 - Las lluvias de Piura. Boletín de la Sociedad Geográfica de Lima, tomo 4: 241-258

GARCÍA ROSELL, R., 1903 - Monografía histórica sobre el Departamento de Piura. Boletín de la Sociedad Geográfica de Lima, 13(4): 455-456.

HAITIN, M., 1985 - Prices, Market, and the agricultural crisis of the late eighteenth century in Peru. Jahrbuch für Geschichte Lateinamerikas (JbLA), No 22: 167-197. CIPCA-UNMSM

HELGUERO, J., 1984[1802-1803] - Informe económico de Piura, 1802, 105p.; Piura:

HOCQUENGHEM, A. M., 1998 - Para vencer la muerte: Piura y Tumbes. Raíces en 
el bosque seco y en la selva alta - horizontes en el Pacífico y en la Amazonía, 445p.; Lima: CNRS-IFEA-INCAH.

HOCQUENGHEM, A. M. \& ORTLIEB, L., 1992 - Eventos El Niño y lluvias anormales en la costa del Perú : siglos XVI-XIX. Bulletin de l'Institut Français d'Études Andines, 21(1): 197-278.

HUERTAS VALLEJO, L., 1984 - Tierras, Diezmos y Tributos en el Obispado de Trujillo (Colonia-República), 273p.; Lima.

MACERA, P., 1992 - Los precios del Perú. Siglos XVI-XIX. Fuentes, vol. 1, Lima: Banco Central de reserva del Perú.

OUWENEEL, A. \& BIJLEVELD, C., 1989 - The Economic Cycle in Bourbon Central Mexico: a Critique of the Recaudación del diezmo líquido en peso. The Hispanic American Historical Review, 69(3): 479-530.

RAMÍREZ ADRIANZÉN, M., J., 1966 - Huancabamba, su Historia, su Geografia, su Folklore. 349p.; Lima.

SCHLÜPMANN, J., 1993 - Commerce et navigation dans l'Amérique Espagnole Coloniale : le port de Paita et le Pacifique au XVIIIème siècle. Bulletin de l'Institut Français d'Études Andines, 22(2): 521-549.

SCHLÜPMANN, J., 1993-1994 - La structure agraire et le développement d'une société régionale au nord du Pérou. Piura, 1588-1854. Thèse de doctorat, inédite, Université de Paris VII-Denis Diderot, 2 tomes, 688p.

TANDETER, E., 1995 - Población y economía en los Andes (siglo XVIII). Revista Andina, año 13, $\mathbf{n}^{0}$ 1: 7-22.

TEPASKE, J. \& KLEIN, H., 1982 - The royal treasuries of the spanish empire in America, vol. I, Peru. 563p.; Durham: Duke University Press. 
Annexe - Les montants de l'affermage de la dîme à Piura, 15891860 (en pesos de 8 réaux).

\begin{tabular}{|c|c|c|c|c|c|c|c|c|}
\hline Bienio & Gruesa & Noveno & $\begin{array}{r}\text { Huanca } \\
\text { bamba }\end{array}$ & Ayabaca & Catacaos & $\begin{array}{r}\text { Chira } \\
\text { y Tumbes }\end{array}$ & $\begin{array}{r}\text { Santa } \\
\text { Ana } \\
\end{array}$ & \\
\hline $1589-1590$ & - & - & - & 320 & - & - & & \\
\hline $1600 *$ & $1811,, 2$ & 201,2 & - & - & - & - & & \\
\hline $1601 *$ & $1856,, 2$ & 206,2 & - & - & - & - & & \\
\hline $1602 *$ & $1884,, 3$ & 211,7 & - & - & - & - & & \\
\hline $1603 *$ & $1913,, 5$ & 212,5 & - & - & - & - & & \\
\hline $1604^{*}$ & 1800,0 & 200 & - & - & - & - & & \\
\hline $1605^{*}$ & $1856,, 2$ & 206,2 & - & - & - & - & & \\
\hline $1606^{*}$ & $1856,, 2$ & 206,2 & - & - & - & - & & \\
\hline $1636^{*}$ & - & - & 710 & - & - & - & & \\
\hline $1645^{*}$ & 4747,4 & 403,4 & - & - & - & - & & \\
\hline $1653 *$ & 4747,44 & - & - & - & - & - & & \\
\hline $1658^{*}$ & - & - & - & - & - & 850 & & \\
\hline $1662 *$ & - & - & - & - & - & 810 & & \\
\hline $1680^{*}$ & - & - & - & 1240 & 500 & 800 & & 400 \\
\hline $1688^{*}$ & - & - & - & - & - & - & & 300 \\
\hline $1690^{*}$ & 5455 & - & - & - & - & - & & \\
\hline $1691^{*}$ & 6250 & - & - & - & - & - & & \\
\hline $1692 *$ & 6400 & - & - & - & - & - & & \\
\hline $1697-1698$ & 15500 & $1620,, 4$ & - & - & - & - & & \\
\hline $1699-1700$ & 16000 & $1673,, 4$ & - & - & - & - & & \\
\hline $1701-1702$ & 18000 & $1881,, 4$ & - & - & - & - & & \\
\hline $1703-1704$ & 18000 & $1881,, 4$ & - & - & - & - & & \\
\hline $1705-1706$ & 16200 & 1694,0 & - & - & - & - & & \\
\hline $1707-1708$ & 16300 & $1704,, 2$ & - & - & - & - & & \\
\hline $1709-1710$ & 16300 & 1704,0 & - & - & - & - & & \\
\hline $1711-1712$ & - & & - & 5200 & - & 3400 & & \\
\hline $1716^{*}$ & - & - & 1800 & - & - & - & & \\
\hline $1721-1722$ & - & - & 2700 & - & - & - & & \\
\hline $1725-1726$ & 18000 & $1881,, 6$ & - & - & - & - & & \\
\hline $1727-1728$ & $?$ & - & - & - & - & - & & \\
\hline $1729-1730$ & 18600 & $1944,, 5$ & - & - & - & - & & \\
\hline $1731-1732$ & 21000 & $2195,, 3$ & - & - & - & - & & \\
\hline $1733-1734$ & 19200 & $2007,, 2$ & - & - & - & - & & \\
\hline $1735-1736$ & 20000 & 2090,3 & - & - & - & - & & \\
\hline $1737-1738$ & 17600 & 1840 & 3600 & - & - & - & & \\
\hline $1739-1740$ & 17300 & 1808 & - & 5200 & - & - & & \\
\hline
\end{tabular}




\begin{tabular}{|c|c|c|c|c|c|c|c|}
\hline $1741-1742$ & 16400 & 1713 & 4100 & - & - & - & - \\
\hline $1743-1744$ & 18980 & 1984 & - & - & - & - & 3800 \\
\hline $1745-1746$ & 21500 & $2247,, 4$ & - & - & - & - & - \\
\hline $1747-1748$ & 21180 & 2214 & - & - & - & - & - \\
\hline $1749-1750$ & 22280 & 2329 & - & - & - & - & - \\
\hline $1751-1752$ & 24760 & $2587,, 6$ & - & - & - & - & - \\
\hline $1753-1754$ & 25000 & ? & 5569,6 & $6042,, 6$ & 1100 & 5918 & $6369,, 4$ \\
\hline $1755-1756$ & 25742 & 2691,2 & - & - & - & - & 6530 \\
\hline $1757-1758$ & 27720 & 2898 & - & - & - & - & - \\
\hline $1759-1760$ & 15840 & 1656 & - & - & - & - & 5650 \\
\hline $1761-1762$ & 20500 & $2121,, 4$ & - & - & - & - & - \\
\hline $1763-1764$ & 20000 & 2070 & 4700 & 4850 & 900 & 4800 & 4750 \\
\hline $1765-1766$ & 19550 & 2039 & 4550 & 4850 & 900 & 4650 & 4600 \\
\hline $1767-1768$ & 21475 & $2222,, 6$ & 5350 & 5400 & 1050 & 5025 & 4650 \\
\hline $1769-1770$ & 18242 & 1888 & 4300 & 5100 & 900 & 3942 & 4000 \\
\hline $1771-1772$ & 18200 & 1898,4 & $4113,, 6$ & $5619,, 5$ & $874,, 5$ & 3847 & 3745 \\
\hline $1773-1774$ & 19000 & 2111 & - & - & - & - & - \\
\hline $1775-1776$ & 18500 & 2055 & - & - & - & - & - \\
\hline $1777-1778$ & 16850 & $1872,, 1_{-}$ & 4200 & 5000 & 500 & 3300 & 3850 \\
\hline $1779-1780$ & - & - & - & - & - & - & - \\
\hline $1781-1782$ & 17250 & - & 3000 & 5000 & 550 & 4100 & 4600 \\
\hline $1783-1784$ & 18100 & - & 3300 & 4500 & 500 & 4500 & 5600 \\
\hline $1785-1786$ & 23070 & - & 4000 & 5635 & 850 & 5525 & 7060 \\
\hline $1787-1788$ & 23600 & - & 3800 & 6500 & 825 & 5200 & 7275 \\
\hline $1789-1790$ & 24060 & - & 4530 & 5300 & 700 & 5830 & 7700 \\
\hline 1791-1792 & 26160 & - & - & - & - & - & - \\
\hline $1793-1794$ & 25850 & - & 4400 & 6000 & 700 & 6650 & 8100 \\
\hline $1795-1796$ & 17725 & - & 3500 & 5500 & 450 & 4275 & 4000 \\
\hline $1797-1798$ & 18725 & - & 3900 & 6500 & 325 & 4000 & 4000 \\
\hline $1799-1800$ & 22475 & - & 3950 & 7025 & 600 & 4800 & 6100 \\
\hline 1801-1802 & 21810 & - & 3810 & 6000 & 700 & 5000 & 6300 \\
\hline $1803-1804$ & 26285 & - & 4000 & 6940 & 720 & 6975 & 7650 \\
\hline $1805-1806$ & 24425 & - & 3600 & 7050 & 900 & 5875 & 7000 \\
\hline $1807-1808$ & - & - & - & - & - & - & - \\
\hline $1809-1810^{\mathrm{a}}$ & 25500 & - & - & - & - & - & - \\
\hline $1811-1812^{\mathrm{a}}$ & 25500 & - & - & - & - & - & - \\
\hline $1813-1814$ & 23500 & - & - & - & - & - & - \\
\hline $1815-1816$ & 23735 & - & - & - & - & - & - \\
\hline $1823-1824$ & 23650 & - & 3500 & 4200 & 650 & 7000 & 8300 \\
\hline $1825-1826$ & 22422 & - & - & - & - & - & - \\
\hline $1827-1828$ & 25149 & - & - & - & - & - & - \\
\hline $1829-1830$ & 20000 & - & - & - & - & - & - \\
\hline $1831-1832$ & 18180 & - & - & - & - & - & - \\
\hline
\end{tabular}




\begin{tabular}{|rrrrrrrr|}
\hline $1833-1834$ & 12120 & - & - & - & - & - & - \\
$1835-1836$ & 17975 & - & - & - & - & - & - \\
$1837-1838$ & 22950 & - & 2750 & 3750 & 750 & 9900 & 5800 \\
$1839-1840$ & 17540 & - & - & - & - & - & - \\
$1841-1842$ & 8875 & - & - & - & - & - & - \\
$1843-1844$ & 10300 & - & - & - & - & - & - \\
$1845-1846$ & 12000 & - & - & - & - & - & - \\
$1847-1848$ & - & - & - & - & - & - & - \\
$1849-1850$ & 12010 & - & - & - & - & - & - \\
$1851-1852$ & - & - & - & - & - & - & - \\
$1853-1854$ & 17243 & - & - & - & - & - & - \\
$1855-1856$ & - & - & 1750 & - & 500 & 3605 & 2775 \\
$1857-1858$ & 11550 & - & - & - & - & - & - \\
$1859-1860$ & 11640 & - & - & - & - & - & - \\
& & & & & & & \\
\hline
\end{tabular}

*affermage pour une année seulement. ${ }^{\text {a }}$ En 1809, la dîme fut affermée sur 4 années consécutives pour un montant de 51.000 pesos.

Source : AGI, Contaduría 1862. AGN, Cajas Reales Piura, leg. 1206-1222. AEP. Epoca colonial, causas civiles, leg. 5, exp. 63, 1770; leg. 6, exp. 71, 1772; leg. 8, exp. 95, 1781; exp. 99, 1783; exp. 102, 1785; exp. 108, 1787; exp. 112, 1789; leg. 9, exp. 116bis, 1793; exp. 123, 1791; leg. 10, exp. 126, 1795; exp. 142, 1799 ; Lorenzo Huertas Vallejo, Tierras, Diezmos y Tributos en el Obispado de Trujillo (Colonia-República), p. 177. M. Justino Ramirez, Huancabamba, su Historia, su Geografia, su Folklore, p.63. 